\title{
Characterization of the Anti-HLA Class I and II IgG Antibodies in Moroccan IVIg Using Regular Beads and Ibeads in Luminex Multiplex Single Antigen Immunoassay
}

\author{
Fatiha EL Hilali $^{1}$, , Vadim Jucaud ${ }^{2}$, Hajar EL Hilali ${ }^{1}$, Mohammed Hassan Bhuiyan ${ }^{3}$, \\ Andrew Mancuso ${ }^{3}$, Nancy LiuSullivan ${ }^{3}$, Abdeslem Elidrissi ${ }^{3}$, Hamid Mazouz ${ }^{1}$ \\ ${ }^{1}$ Department of Biology, Faculty of Sciences, Moulay Ismail University, Meknes, Morocco \\ ${ }^{2}$ Terasaki Foundation Laboratory, California, USA \\ ${ }^{3}$ Department of Biology, College of Staten Island, City University of New York, New York, USA
}

Email address:

hfatiha@gmail.com (F. E. Hilali), vjucaud@terasakilab.org (V. Jucaud), elhajar83@gmail.com (H. E. Hilali), Mhbhuiy@gmail.com (M. H. Bhuiyan), amancuso934@gmail.com (A. Mancuso), Nancy.LiuSullivan@csi.cuny.edu (N. LiuSullivan), Abdeslem.Elidrissi@csi.cuny.edu (A. Elidrissi),ham_Mazouz@yahoo.fr (H. Mazouz)

${ }^{*}$ Corresponding author

\section{To cite this article:}

Fatiha EL Hilali, Vadim Jucaud, Hajar EL Hilali, Mohammed Hassan Bhuiyan, Andrew Mancuso, Nancy LiuSullivan, Abdeslem Elidrissi, Hamid Mazouz. Characterization of the Anti-HLA Class I and II IgG Antibodies in Moroccan IVIg Using Regular Beads and Ibeads in Luminex Multiplex Single Antigen Immunoassay. International Journal of Immunology. Vol. 5, No. 4, 2017, pp. 53-65. doi: 10.11648/j.iji.20170504.11

Received: May 15, 2017; Accepted: May 23, 2017; Published: July 18, 2017

\begin{abstract}
Therapeutic Immunoglobulin Intravenous (IVIg), approved to treat a wide range of autoimmune and primary immunodeficiency diseases, contain mixture of polyreactive and polyclonal IgG purified from the pooled plasma of thousands of donors. The aim of this study is to characterize the profiles of anti- Human Leukocyte Antigen (HLA) class-I and class-II IgG antibodies in four lots of Moroccan IVIg preparations using Luminex Multiplex Single Antigen Bead Immunoassay and to compare it with the unique high frequency HLA types found in the Moroccan population. Anti-HLA class I IgG profiles were assessed using regular (Labscreen) Beads and iBeads. The regular beads are coated with all conformational and structural variants of HLA-I (HLA heavy chain (HC) with $\beta 2$-microglobulin $(\beta 2 \mathrm{~m})$ with or without peptides, $\beta 2 \mathrm{~m}$-free HC with or without peptides or $\mathrm{HC}$ only), quite contrast to iBeads, which contained only native tissue-associated HLA HC with $\beta 2 \mathrm{~m}$ and with or without peptides. The level of antibodies was measured as Mean Fluorescent Intensity (MFI). The reactivity of antiHLA-I IgG antibodies to different alleles of HLA-I loci differed in their recognition of native HLA-I and other structural variants of the HLA-I. High MFI IgG antibodies in the IVIg corresponded with several high frequency HLA-I alleles (B*0801, B*5001, Cw*0602 and Cw*0702) and HLA-II haplotypes (DQA1*0201-DQB $1 * 0201 / \mathrm{DRB} 1 * 0301$ ), which accounted for $50 \%$ of the total gene frequencies in the Moroccan population. HLA-I reactivity of the IVIg with iBeads confirms that the IgG reacting to normal tissue associated with peptide -associated or -free $\beta 2 \mathrm{mHC}$. These findings caution the use of high dose IVIg for the carriers of the high frequency HLA types for it may cause tissue injury. The $\beta 2 \mathrm{~m}$-free-HC reactivity of IVIg indicates the potential of IVIg to bind to activated T and B cells that express these variants, to suppress antibody production. Such an immunomodulation by IVIg renders benefit for patients with autoimmune diseases and organ transplantation.
\end{abstract}

Keywords: Intravenous Immunoglobulin, HLA, Antibodies, Moroccan IVIg, Beads, Ibeads, MFI

\section{Introduction}

When Immunoglobulin (Ig) therapy was replaced by Intravenous Immunoglobulin (IVIg) with sera derived from multiethnic population from Morocco, the IVIg was not affordable for most patients, until the Blood Transfusion and Hematology National Center and Fractionation and Biotechnologies French Laboratory (LFB-France) industry subcontracted IVIg production using plasma from Moroccan 
blood donors [1], which included both allo-immunized and non-alloimmunized males and females. As a result, the cost of IVIg therapy is reduced by about $66 \%$ [1]. Consequently Moroccan IVIg therapy is administered to primary deficiency, autoimmune and neurological diseases, including Guillain-Barre syndrome, for which it was found to be safer and effective alternative to standard therapies [2]. However, very little effort has been made to characterize the composition of Moroccan IVIg, pooled and purified from the plasma of Moroccan population, which has remarkable ethnic and genomic diversities, which is reflected in their Human Leukocyte Antigen (HLA) typing profiles. As of March 2017, it has been reported that the Human major histocompatibility complex includes highly polymorphic proteins of classical HLA class I (HLA-A [ $\mathrm{n}=2747]$, -B [ $\mathrm{n}=$ 3465], and $-\mathrm{C}[\mathrm{n}=2450])$ proteins and HLA-II (HLA-DRA $[\mathrm{n}=7]$, -DRB [ $\mathrm{n}=1711]$, -DQA1 [n=34], -DQB1 [n=761], -DPA1 $[\mathrm{n}=23]$ and -DPB1 $[\mathrm{n}=627]$ proteins [3]. Studies examining HLA-I types in Casablanca, the largest region of Morocco, reported that the most frequent types were HLAA2 (21\%), -A1 (11\%), -A3 (10\%), -B44 (11.4\%), -B50 (9.9\%), -B5 (8.5\%) and -B35 (6.5\%) [4]. Similarly, in the Amazigh ethnic group, the most frequent alleles were HLAA*0201, A*0101; HLA-B*4403, B*4402, B*0801, B*5001, $\mathrm{B} * 5002 ; \quad \mathrm{HLA}-\mathrm{Cw} * 0602, \quad \mathrm{Cw} * 070101, \quad \mathrm{Cw} * 070102$, $\mathrm{CW}^{*} 0702, \mathrm{CW}^{*} 0704$, and $\mathrm{CW}^{*} 0706, \mathrm{CW}^{*} 040101$ [5]. Molecular typing of HLA-II in Amazigh group (Souss) revealed high frequencies for DRB1*0701, DRB1*0301, DQA $1 * 0501$, DQA $1 * 0201$, and DQB $1 * 0201$ [6]. Three haplotypes $\quad(\mathrm{DRB} 1 * 0701-\mathrm{DQA} 1 * 0201-\mathrm{DQB} 1 * 0201$, DRB1*0301-DQA1*0501-DQB1*0201 and DRB1*11DQA $1 * 0501-\mathrm{DQB} 1 * 0301$ ) are accounted for nearly $50 \%$ of the total gene frequencies. Many other studies on HLA typing of Moroccan population have confirmed the above mentioned high frequency types in the Moroccan population [7-10]. On the other hand, it is also well established that IgG antibodies against HLA-I and -II molecules do occur naturally as auto- or allo-antibodies in non-alloimmunized males [11 -20]. The origin of these antibodies in "so-called" healthy individuals is still far from clear. It remains to be seen whether the HLA antibodies in the Moroccan healthy blood donors reflect the HLA types of the population and whether they are auto-antibodies, which means, directed against self-antigens, as has been reported elsewhere [21, 22]. High level of anti-HLA antibodies are reported in several autoimmune diseases [22, 23]. Therefore, it is felt that the Moroccan IVIg may reflect the HLA profiles of the Moroccan population. Examination of the anti-HLA IgG antibody profiles of Moroccan IVIg preparations may validate the above assumption.

There is also yet another need to characterize HLA-I and II antibodies in Moroccan IVIg, because IVIg may be administered to patients with Transfusion-related Acute Lung Injury (TRALI), while it is well established that the causal factor of TRALI is the presence of HLA antibodies in the patients. There are many reports on the occurrence of TRALI after IVIg administration [24-29]. Anti-HLA-II IgG observed in patients after plasma transfusion is implicated in TRALI [26]. The anti-HLA-II IgG binding to monocytes in patients with TRALI may induce activation of neutrophils that may penetrate the endothelium of lungs, causing destruction of the endothelial cells [24, 30]. Presence of HLA-II antibodies in allo-immunized females led to prevention of using blood from females for transfusion, Therefore, the avoidance of female blood has become routine as a preventive measure against TRALI in several countries [31, 32]. It was reported that this policy did indeed significantly reduce the incidence of TRALI both in large-scale surveillance studies and haemovigilance reports [32].

Furthermore, it is perplexing to note that $\mathrm{IgG}$ antibodies to allo-HLA proteins are common in sera after transfusions, organ transplantation, and autoimmune diseases [21-23, 33 35]. After all, Moroccan IVIg is prepared from plasma from over 40000 male and female healthy donors, but certainly with a history of infection, inflammation, injuries and unknown immune related diseases.

Therefore, the primary specific objective of this investigation is to characterize IgG reactivity against HLA-I and HLA-II in Moroccan IVIg. Such an investigation is necessary to determine whether the therapeutic application of IVIg should be preceded by HLA antibody screening. Commercially available IVIg preparations, depending on their polyreactive and their polyclonal antibody strength may contain variable amounts of IgG dimers in the range of 5$15 \%$ [36], although IgG dimer, unlike polymers, does not cause anaphylactic shock. Nevertheless IVIg preparations with high dimer content are less tolerated and can give rise to undesirable side effects such as fever, nausea and sometimes lowered blood pressure [37, 38]. Therefore, our second objective is to evaluate Moroccan IVIg formulation for dimer composition.

\section{Materials and Methods}

\subsection{Source and Preparation of IVIg}

In Morocco, IVIg is prepared from the whole blood of 40 000 male and female donors. The Moroccan IVIg is manufactured according to the Kistler-Nitschmann method, involving cryoprecipitation, multiple (11\% 16\% and 22\%) ethanolic precipitations, viral inactivation, viral and prion filtration, acidic and enzymatic treatments, sterilization, and lyophilization. All four lots were received as lyophilized powder and were reconstituted with water for injection at a concentration of $50 \mathrm{mg} / \mathrm{mL}$ (or $5 \%$ proteins). All the IVIg preparations contained $\operatorname{IgA}(17 \mathrm{mg} / \mathrm{g}$ of protein), traces of pepsin, sucrose and sodium. Most of the IVIg preparations from US and Europe are devoid of sucrose, due to adverse reports after IVIg administration to patients [38]. The source of IVIg is: (Immunoglobuliline Normale IV-LFB-CNTs (50 $\mathrm{mg} / \mathrm{ml}$ ) 2015, LFB Biomedicaments. Courtaboeuf Cedex, France). The details of the lots are as follows: Lot\#1: 14L 00532; Lot\#2: 14L 00534; Lot\#3: 14L 01611; Lot\#4: 14L 01617. 


\subsection{Determination of Monomer/Dimer Ration with Fast Protein Liquid Chromatography (FPLC)}

The four lots of IVIg preparations $(50 \mathrm{mg} / \mathrm{ml})$ were initially diluted with normal saline $(0.9 \% \mathrm{NaCl})$ to $10 \mathrm{mg} / \mathrm{mL}$, and examined within 24 hours, by FPLC using a superdex G-200 column $(1.5 \times 50 \mathrm{~cm})$ pre-equilibrated with $50 \mathrm{mM}$ sodium phosphate/150mM sodium chloride at $\mathrm{pH}$ 7.2, using Amersham Biosciences AKTA Purifier FPLC System (includes: Box 900; CU-950 System Interface; pH/C-900 Conductivity Detector; Amersham UV-900 UV/Monitor; Amersham P-900 Pump). The flow rate was maintained at $3 \mathrm{ml} /$ tube after $0.5 \mathrm{ml}$ of IVIg was loaded onto the column. The ratio of monomer/ dimer is determined as follows: [monomer/dimer] $\times 2$. The percentage of monomers and dimers was determined as follows: monomer x 2 x100/ [dimer+ (monomer x 2)].

(1) Dimer $\%=(1 / 2) *($ dimer integral $) /((1 / 2) *$ dimer intergral + monomer integral $)$; and

(2) Monomer $\%=($ monomer integral $) /$ (monomer integral $+(1 / 2)^{*}$ dimer integral).

\subsection{Matrix-Assisted Laser Desorption/Ionization Time-of-Flight Mass Spectrometry (MALDI-TOF MS)}

Molecular sizes of the protein fractions in the four lots of IVIg were assessed to ascertain the presence of monomeric IgG fractions, their degradation, if any, following a standard protocol [39] using MALDI-TOF MS. The IVIg preparations $(10 \mathrm{mg} / \mathrm{mL})$ were analyzed using a microflex LT Matrixassisted laser desorption/ionization time-of-flight mass spectrometry (MALDI-TOF MS) instrument (Bruker Daltonik GmbH, Bremen, Germany). The spectra were recorded in the linear positive mode at a laser frequency of $5.0 \mathrm{~Hz}$ within a mass ranging from 10 to $100 \mathrm{kDa}$ and 100 $\mathrm{kDa}$ to $200 \mathrm{kDa}$. Parameter settings for microflex instrument were ion source 1 at $20 \mathrm{kV}$, ion source 2 at $18.0 \mathrm{kV}$, lens at $9.5 \mathrm{kV}$, pulsed ion extraction of $50 \mathrm{nS}$ and no gating. Mass spectrometry samples were prepared following the protocol [40]. Briefly, $0.5 \mu \mathrm{L}$ of sample was loaded onto a spot on the MALDI-TOF steel target plate, and $0.5 \mu \mathrm{L}$ of the calibration standard (ProteoMass Apomyoglobin MALDI-MS Standard; Sigma-Aldrich) was loaded onto a separate spot.

\subsection{Immunoassay with Single Antigen Beads SABs}

HLA-I and -II IgG reactivity were analyzed using Luminex Multiplex Single Antigen Bead immunoassay. The data obtained with a dual-laser flow-cytometry LuminexxMAP ${ }^{\circledR}$ (http://www.luminexcorp.com/) (LABScanTM100; One Lambda, Canoga Park, CA) [41]. The single recombinant HLA-Ia and HLA-II (rHLA-Ia \& rHLA-II) antigens in LS1A04-Lot 008 (for HLA-Ia) containing 97 HLA-I antigens (31 HLA-A, 50 HLA-B and 16 HLA-Cw) and in LS.2 A01009 (Lot 9) (for HLA-II) containing 91 HLA-II antigens (29 HLA-DRB1, 7 HLA-DRB3, 4, 5, 29 HLA-DQ, 26 HLA-DP). The SAB assay includes built-in control beads, coated with human IgG (positive control) or albumin (human or bovine) (negative control).
For HLA class I, two kinds of beads were used. They are regular Labscreen beads and iBeads [41]. The beads supplied by the manufacturer may have 2 categories of HLA proteins attached to the beads: HLA heavy-chain polypeptide only and heavy-chain polypeptides in association with Beta-2 microglobulin $(\beta 2 \mathrm{~m})$. Realizing the heterogeneity of proteins, the manufacturer recently developed iBeads (provided as Felix beads for in-house experimental use), in which regular HLA-Ia antigencoated microbeads are subjected to proprietary enzymatic treatment to remove or reduce the amount of heavy chains (also referred to as "denatured antigens" by the manufacturers) $[42,43]$.

Briefly, the four lots of IVIg were titrated from 50 to $0.8 \mathrm{mg} / \mathrm{mL}$ (diluted in $1 \mathrm{X}$ PBS, $\mathrm{pH} 7.2$ ), and $20 \mu \mathrm{L}$ of sample were incubated with $2 \mu \mathrm{L}$ of beads for 30 minutes at room temperature and on a shaker. The beads were then washed three times with LabScreen ${ }^{\circledR}$ wash buffer. The HLA-I and -II reactivity were monitored by incubating 50 $\mu \mathrm{L}$ (at $5 \mu \mathrm{g} / \mathrm{mL}$ ) of PE-conjugated Goat anti-human IgG (Fab') for 30 minutes. The beads were washed three times, and then resuspended in $1 \mathrm{X}$ PBS before acquisition. For each sample analysis, at least 100 beads were counted. The IgG reactivity against each HLA-I and -II antigens were recorded as Trimmed Mean Fluorescence Intensity (MFI), and the MFI values are normalized against the negative control (bead \#1) and the negative control (1X PBS). The MFI cutoff used was 1,000 for a positive reaction.

\subsection{Statistical Analysis}

All data were analyzed using statistical software package for PC (version 13; Dell, Inc. Round Rock, Texas). Analyzed groups were tested for normal distribution using ShapiroWalk W testing. Data sets with normal distributions were analyzed by multifactorial ANOVA to identify overall condition effects. Significant differences were determined by post hoc comparisons of means using Tukey's honest significant difference test. Significance was set at a confidence level of $95 \%$. Data are presented as mean \pm SEM.

\section{Results}

\subsection{MALDI-TOF MS Profile of the Four IVIg Lots}

The MALDI-TOF MS spectra analysis of the four different lots of IVIg revealed the presence of 6 main protein peaks (Figure 1). The major peak of $\sim 149 \mathrm{kDa}$ is corresponding to the molecular weight of $\operatorname{IgG}(\sim 150 \mathrm{kDa})$. Prominent prevalence of the mass of $149 \mathrm{kDa}$ suggests that the IgGs in Moroccan IVIg are intact with no obvious degradation.

Four lots (Lots 1-4) of Moroccan IVIg were mixed and crystalized with $\alpha$-Cyano-4- hydroxycinnamic acid (4HCCA) in formic acid: water: isopropanol $(3: 1: 2)$ in a $1: 9$ ratio. The expected mass of Moroccan IgG antibody is $\sim 150$ $\mathrm{kDa}$, the observed species is $\sim 149 \mathrm{kDa}$. Each lot of Moroccan IVIg was collected in two spectrums ranging from $10 \mathrm{kDa}$ to 
$100 \mathrm{kDa}$ and $100 \mathrm{kDa}$ to $200 \mathrm{kDa}$ (shown as one spectrum).

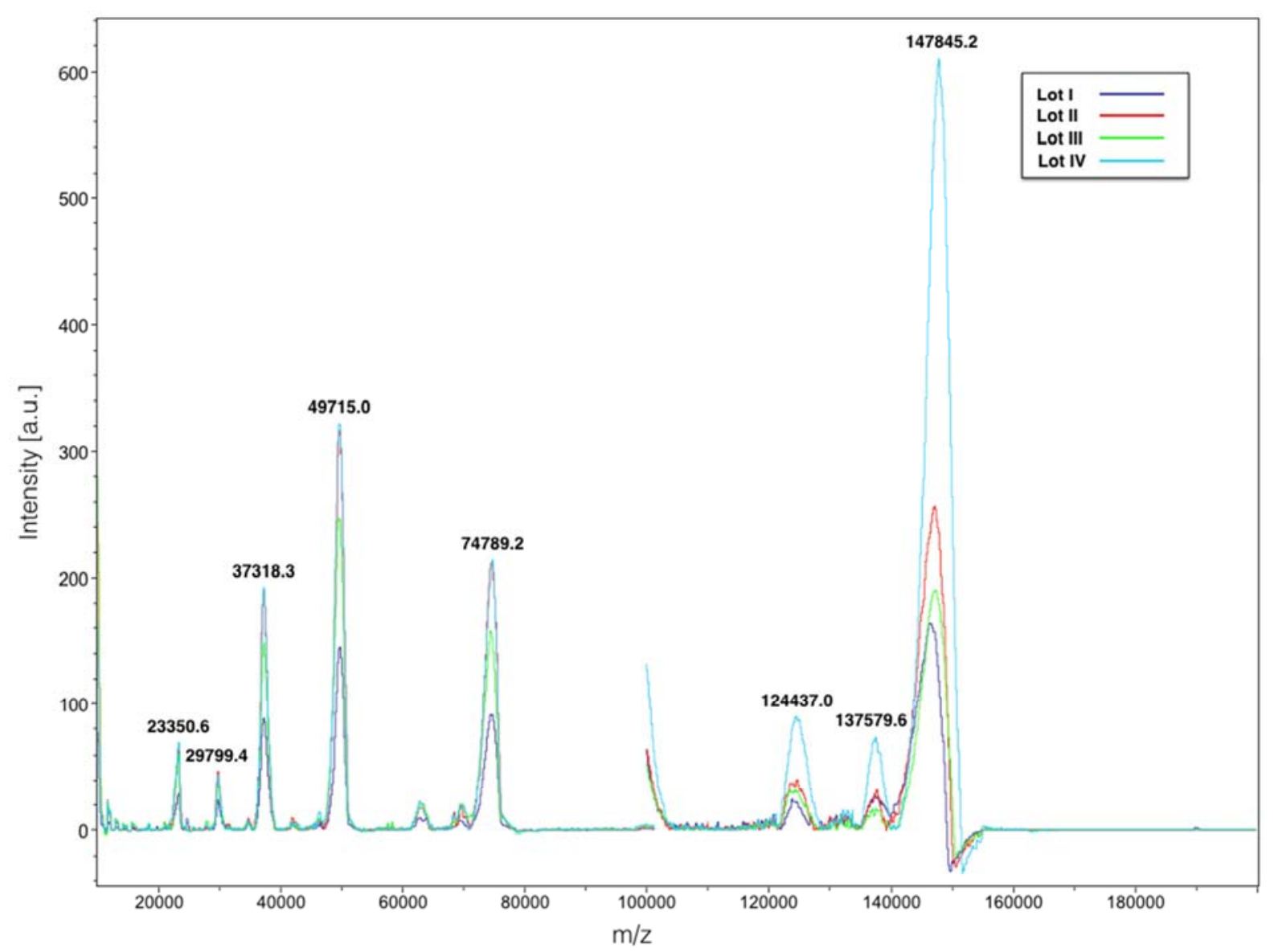

Figure 1. MALDI-TOF MS spectra of the four Moroccan IVIg lots.

\subsection{FPLC Analysis of the Four IVIg Lots}

The FPLC analysis of the four different lots of IVIg showed that all IVIg preparations contain monomeric, dimeric and polymeric IgG (Figure 2, Table 1). The highest peak corresponds to monomeric $\mathrm{IgG}$, the second highest corresponds to dimeric IgG, and the lowest is indicative of polymeric IgG. Table 1 shows the percentage of monomer and dimer of IgG in all IVIg lots tested. IVIg lot\# 4 being the highest dimer percentage (11\%), followed by IVIg lot \# 3 (9.9\%), IVIg lot\# 1 (6.4\%), and IVIg lot\# 2 (5.8\%). The amount of polymeric IgG is negligible in all IVIg lots tested.

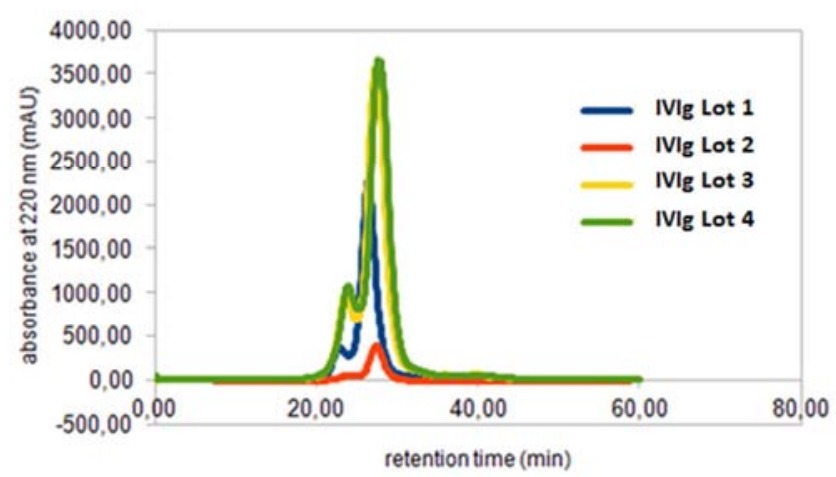

Figure 2. FPLC chromatogram of the four Moroccan IVIg lots \#1; 2; 3; 4.
The highest peak corresponds to monomeric IgG, the second highest corresponds to dimeric $\mathrm{IgG}$, and the lowest to polymeric IgG.

Table 1. Fast protein liquid chromatography (FPLC) analysis.

\begin{tabular}{|c|c|c|c|c|c|}
\hline \multirow{2}{*}{$\begin{array}{l}\text { IVIg } \\
\text { Lots }\end{array}$} & Dimer & Monomer & \multirow{2}{*}{$\begin{array}{l}\text { Monomer/Dimer } \\
\text { ratio }\end{array}$} & \multirow{2}{*}{$\begin{array}{l}\text { Monomer } \\
(\%)\end{array}$} & \multirow{2}{*}{$\begin{array}{l}\text { Dimer } \\
(\%)\end{array}$} \\
\hline & $\begin{array}{l}\text { Peak } \\
\text { Area }\end{array}$ & $\begin{array}{l}\text { Peak } \\
\text { Area }\end{array}$ & & & \\
\hline$\# 1$ & 704.45 & 5111.28 & 14.51 & 93.6 & 6.4 \\
\hline \#2 & 113.06 & 925 & 16.36 & 94.2 & 5.8 \\
\hline \# 3 & 2130.7 & 9737.48 & 9.14 & 90.1 & 9.9 \\
\hline \# 4 & 2427.08 & 9831.51 & 8.1 & 89 & 11 \\
\hline
\end{tabular}

Percentage of monomer and dimer of the four Moroccan IVIg.

\subsection{Anti-albumin Reactivity of the Four IVIg Lots}

All the IVIg lots reacted with the negative control beads coated with albumin (Figure 3), indicating that the Moroccan IVIg preparations contain naturally occurring anti-albumin antibodies, almost a similar inference can be derived from a previous report monitoring anti-HLA antibodies of Moroccan sera [44]. Among the four IVIg lots, lot \#1 showed the highest anti-albumin reactivity, followed by lot \# 2, then lot \# 3 , and finally lot \# 4 showed the least reactivity. 


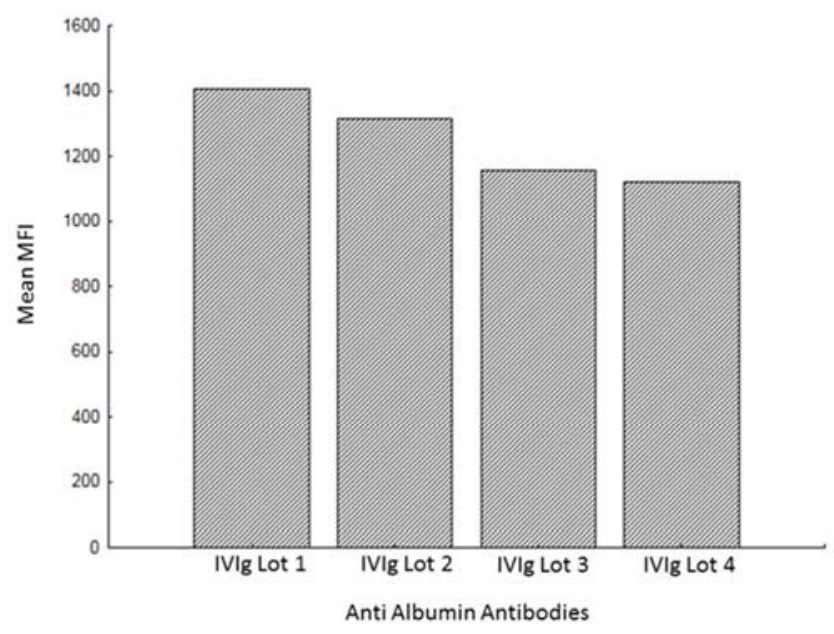

Figure 3. Mean MFI values of Anti-albumin at a concentration of $50 \mathrm{mg} / \mathrm{mL}$ of the four Moroccan IVIg lots.

All the four IVIg lots reacted with the negative control beads coated with albumin, lot\#1 showed the highest reactivity.

\subsection{Anti-HLA-I and Anti-HLA-II IgG Reactivity of the Four IVIg Lots Using Regular Labscreen Beads}

All IVIg lots recognize most of the HLA class-Ia alleles and HLA-II molecules. All preparations reacted with all beads coated with HLA-I and HLA-II alleles. However, for HLA-A and HLA-B alleles, there were no alleles reactive to any of the IVIg lots at 1:32 dilution. In contrast, HLADRB345 and HLA-DP alleles showed reactivity even at highest dilution 1/64 (Table 2).

Table 2. Number of HLA-Ia and HLA-II alleles reactive to the four Moroccan IVIg.

\begin{tabular}{|c|c|c|c|c|c|c|c|c|}
\hline \multirow[t]{2}{*}{ IVIg Lots } & \multirow[t]{2}{*}{ Dilutions } & \multicolumn{7}{|c|}{$\begin{array}{l}\text { Number of HLA-Ia and HLA-II alleles } \\
\text { reactive to IVIg }\end{array}$} \\
\hline & & $\mathbf{A}$ & B & $\mathrm{Cw}$ & DRB1 & DRB345 & DQ & DP \\
\hline \multirow{7}{*}{ \# 1} & {$[1 / 64]$} & 0 & 0 & 0 & 0 & 1 & 0 & 1 \\
\hline & {$[1 / 32]$} & 0 & 0 & 0 & 7 & 2 & 0 & 10 \\
\hline & [1/16] & 0 & 0 & 7 & 11 & 5 & 1 & 15 \\
\hline & {$[1 / 8]$} & 2 & 3 & 15 & 22 & 5 & 10 & 21 \\
\hline & {$[1 / 4]$} & 24 & 38 & 16 & 28 & 7 & 29 & 26 \\
\hline & {$[1 / 2]$} & 29 & 48 & 16 & 29 & 7 & 29 & 26 \\
\hline & Neat & 31 & 50 & 16 & 29 & 7 & 29 & 26 \\
\hline \multirow{7}{*}{ \# 2} & [1/64] & 0 & 0 & 0 & 0 & 1 & 0 & 0 \\
\hline & {$[1 / 32]$} & 0 & 0 & 0 & 1 & 1 & 0 & 4 \\
\hline & {$[1 / 16]$} & 0 & 0 & 3 & 4 & 2 & 0 & 6 \\
\hline & {$[1 / 8]$} & 1 & 1 & 13 & 14 & 5 & 2 & 16 \\
\hline & {$[1 / 4]$} & 6 & 20 & 16 & 26 & 7 & 20 & 22 \\
\hline & {$[1 / 2]$} & 25 & 44 & 16 & 29 & 7 & 29 & 26 \\
\hline & Neat & 31 & 50 & 16 & 29 & 7 & 29 & 26 \\
\hline \multirow{7}{*}{ \# 3} & {$[1 / 64]$} & 0 & 0 & 0 & 0 & 1 & 0 & 1 \\
\hline & {$[1 / 32]$} & 0 & 0 & 1 & 5 & 2 & 0 & 8 \\
\hline & [1/16] & 0 & 0 & 8 & 8 & 3 & 0 & 10 \\
\hline & {$[1 / 8]$} & 1 & 4 & 14 & 20 & 5 & 6 & 19 \\
\hline & {$[1 / 4]$} & 16 & 32 & 16 & 26 & 7 & 20 & 23 \\
\hline & {$[1 / 2]$} & 28 & 47 & 16 & 29 & 7 & 29 & 26 \\
\hline & Neat & 31 & 50 & 16 & 29 & 7 & 29 & 26 \\
\hline \multirow{3}{*}{ \# 4} & {$[1 / 64]$} & 0 & 0 & 0 & 0 & 1 & 0 & 1 \\
\hline & {$[1 / 32]$} & 0 & 0 & 1 & 1 & 1 & 0 & 3 \\
\hline & [1/16] & 0 & 0 & 8 & 9 & 5 & 0 & 14 \\
\hline
\end{tabular}

\begin{tabular}{lllllllll}
\hline \multirow{3}{*}{ IVIg Lots } & \multirow{8}{l}{$\begin{array}{l}\text { Number of HLA-Ia and HLA-II alleles } \\
\text { reactive to IVIg }\end{array}$} \\
\cline { 2 - 9 } & Dilutions & A & B & Cw & DRB1 & DRB345 & DQ & DP \\
\cline { 2 - 8 } & 2 & 4 & 15 & 23 & 5 & 12 & 21 \\
& {$[1 / 8]$} & 16 & 32 & 16 & 26 & 7 & 20 & 23 \\
& {$[1 / 4]$} & 30 & 49 & 16 & 29 & 7 & 29 & 26 \\
& {$[1 / 2]$} & 31 & 50 & 16 & 29 & 7 & 29 & 26 \\
\hline Neat & \multicolumn{1}{c}{} & & & &
\end{tabular}

All IVIg lots reacted to the panel of the 97 HLA-I (31 HLA-A, 50 HLA-B and 16 HLA-Cw) alleles coated on the regular Labscreen beads using Luminex single-antigen bead (SAB) assays. Figure 4 shows the mean MFI of the undiluted (neat) preparations of each IVIg lot (at $50 \mathrm{mg} / \mathrm{mL}$ concentration) against the HLA-A, $-\mathrm{B}$ and $-\mathrm{Cw}$ loci. The combined allelic mean MFI of pooled HLA-A reactivity of lot $\# 1,2,3$, and 4 was $1865 \pm 710,1946 \pm 893,1560 \pm 655$, and $1566 \pm 585$, respectively. The mean combined allelic mean MFI of pooled HLA-B reactivity of lot $\# 1,2,3$, and 4 was $2090 \pm 619,2228 \pm 693,1786 \pm 579$, and $1706 \pm 524$, respectively. The combined allelic mean MFI of pooled HLA-Cw reactivity of lot $\# 1,2,3$, and 4 was $3656 \pm 1116$, $4189 \pm 1467,3099 \pm 920$, and $2982 \pm 957$, respectively. All IVIg preparations showed stronger reactivity to HLA-Cw alleles, followed by HLA-B alleles and then HLA-A alleles.

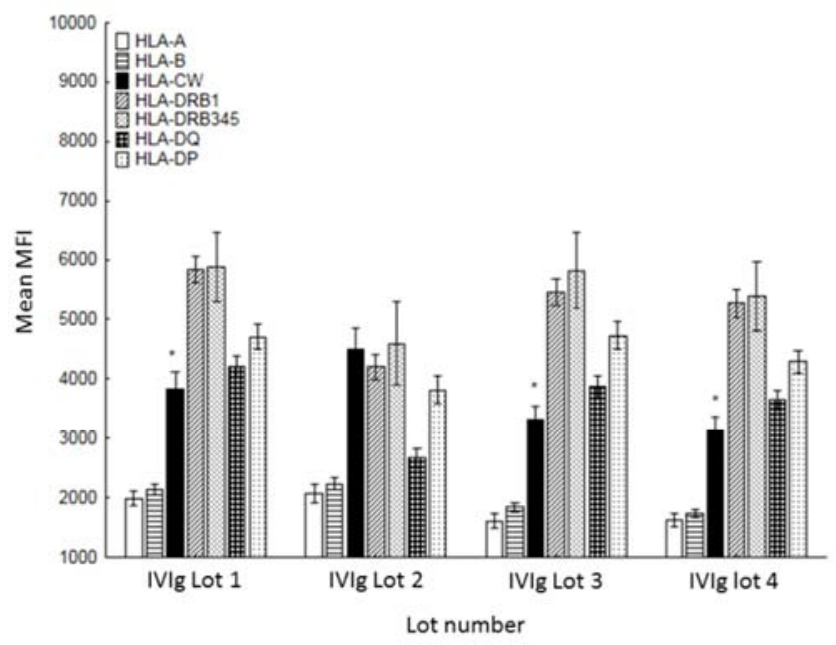

Figure 4. Comparison of the normalized mean fluorescence intensity (MFI) of human leucocyte antigen (HLA) class II immunoglobulin (Ig) G antibodies of the four IVIg lots (at 50mg/mL concentration) against HLA-A ( $n=31)$, HLA-B $(n=50), H L A-C w(n=16), H L A-D R B 1(n=29), H L A-D R B 345(n=7)$, HLA-DQ $(n=29)$, and HLA-DP $(n=26)$ alleles in the HLA-I Single Antigen Bead panel.

Data represent mean \pm SEM. A two-way ANOVA showed a statistically significant interaction between antigens and lots $(\mathrm{F}(18,724)=5.98, \mathrm{p}<.00001)$. There was a significant effect of antigens $(\mathrm{F}(6,724)=234.49, \mathrm{p}<.0001)$ and lots $(\mathrm{F}$ $(3,724)=11.54, \mathrm{p}<0.0001)$. Tukey post Hoc tests reactivity of HLA-A and $\mathrm{B}$ was significantly lower than all other antigens tested $(* \mathrm{P}<.001)$.

Table 3 provides a detailed profile of HLA-I reactivity of different lots of IVIg as MFI of individual alleles of each HLA-I loci. It may be noted that the most prevalent antiHLA-A IgG antibodies in all the Moroccan IVIg lots, as assessed by the MFI strength at neat and $1 / 2$ dilution, are 
A*3401 and $A * 8001$ (indicated by bold italics) and the least expressed anti-HLA-A IgGs are against $A * 0301$ and A*7401. Similarly, the most prevalent anti-HLA-B IgG antibodies in all IVIg lots are $\mathrm{B}^{* 1512}$ and $\mathrm{B} * 8201$. Among
anti-HLA-Cw IgG antibodies, MFI of $\mathrm{Cw}^{*} 0702$ and $\mathrm{Cw}^{*} 1702$ are the most predominant in all lots of the IVIg preparations.

Table 3. HLA-A, HLA-B, and HLA-Cw allelic reactivity of the four lots of Moroccan IVIg determined using regular Labscreen Beads.

\begin{tabular}{|c|c|c|c|c|c|c|c|c|c|c|c|c|c|c|c|c|c|}
\hline \multirow{2}{*}{$\frac{\text { HLA-A }}{\text { Dilution }}$} & \multicolumn{2}{|c|}{ IVIg Lot 1} & \multicolumn{2}{|c|}{ IVIg Lot 2} & \multicolumn{2}{|c|}{ IVIg Lot 3} & \multicolumn{2}{|c|}{ IVIg Lot 4} & \multirow{2}{*}{$\begin{array}{l}\text { HLA-B } \\
\text { Dilution }\end{array}$} & \multicolumn{2}{|c|}{ IVIg Lot 1} & \multicolumn{2}{|c|}{ IVIg Lot 2} & \multicolumn{2}{|c|}{ IVIg Lot 3} & \multicolumn{2}{|c|}{ IVIg Lot 4} \\
\hline & $(1 / 2)$ & Neat & $(1 / 2)$ & Neat & $(1 / 2)$ & Neat & $(1 / 2)$ & Neat & & $(1 / 2)$ & Neat & $(1 / 2)$ & Neat & $(1 / 2)$ & Neat & $(1 / 2)$ & Neat \\
\hline$A * 0101$ & 952 & 1865 & 547 & 1772 & 683 & 1389 & 984 & 1543 & $B * 0702$ & 1855 & 2933 & 1390 & 3414 & 1714 & 2701 & 1899 & 2468 \\
\hline$A^{*} 0201$ & 862 & 1651 & 615 & 1662 & 778 & 1472 & 878 & 1398 & $B * 0801$ & 1954 & 3191 & 1383 & 3370 & 1700 & 2909 & 2053 & 2710 \\
\hline$A^{*} 0203$ & 797 & 1683 & 553 & 1527 & 671 & 1324 & 871 & 1325 & $B * 1301$ & 1251 & 2447 & 912 & 2615 & 1161 & 2022 & 1377 & 1951 \\
\hline A*0206 & 917 & 1654 & 691 & 1946 & 874 & 1492 & 967 & 1451 & $B * 1302$ & 938 & 1911 & 727 & 2033 & 886 & 1719 & 964 & 1578 \\
\hline$A^{*} 0301$ & & 734 & & 737 & & 576 & & 579 & $B * 1401$ & 1487 & 2593 & 1219 & 2646 & 1488 & 2157 & 1592 & 1934 \\
\hline A*1101 & 1264 & 2013 & 808 & 2346 & 972 & 1585 & 1337 & 1685 & $B * 1402$ & 1456 & 2484 & 1154 & 2690 & 1377 & 2136 & 1609 & 2031 \\
\hline A*1102 & 735 & 1590 & & 1456 & 576 & 1183 & 753 & 1395 & $B * 1501$ & & 863 & & 801 & & 818 & & 620 \\
\hline A*2301 & 679 & 1368 & & 1323 & 543 & 1112 & 764 & 1157 & $B * 1502$ & 1152 & 1917 & 915 & 2208 & 1126 & 1745 & 1198 & 1584 \\
\hline$A * 2402$ & 1361 & 2127 & 884 & 2381 & 1004 & 1768 & 1390 & 1948 & $B * 1503$ & & 1166 & & 1167 & & 912 & 631 & 818 \\
\hline$A * 2403$ & 1441 & 2271 & 847 & 2002 & 1131 & 1750 & 1578 & 1846 & $B * 1510$ & 957 & 2018 & 675 & 1887 & 895 & 1583 & 1071 & 1539 \\
\hline$A * 2501$ & 1016 & 1793 & 790 & 1699 & 904 & 1615 & 975 & 1449 & $B * 1511$ & 1047 & 1881 & 724 & 1755 & 835 & 1428 & 1192 & 1564 \\
\hline$A * 2601$ & 1272 & 2363 & 810 & 2556 & 1017 & 1885 & 1178 & 1835 & $B * 1512$ & 2341 & 2972 & 1747 & 3017 & 2210 & 2742 & 2327 & 2557 \\
\hline$A * 2901$ & 1196 & 2384 & 890 & 2469 & 1072 & 1860 & 1322 & 1858 & $B * 1513$ & 794 & 1463 & 569 & 1424 & 652 & 1111 & 925 & 1141 \\
\hline A*2902 & 1522 & 2859 & 1141 & 3365 & 1366 & 2431 & 1650 & 2316 & $B * 1516$ & 1576 & 2331 & 1209 & 2750 & 1415 & 2015 & 1597 & 1987 \\
\hline$A * 3001$ & 892 & 1708 & 542 & 1555 & 634 & 1219 & 910 & 1320 & $B * 1801$ & 710 & 1473 & 501 & 1706 & 640 & 1285 & 745 & 1169 \\
\hline$A * 3002$ & 1003 & 1832 & 783 & 1878 & 969 & 1560 & 1049 & 1566 & $B * 2705$ & 802 & 1768 & 659 & 1999 & 861 & 1612 & 907 & 1405 \\
\hline$A * 3101$ & 926 & 1798 & 623 & 1974 & 800 & 1519 & 1001 & 1397 & $B * 2708$ & 1366 & 2552 & 1240 & 2713 & 1525 & 2275 & 1437 & 2022 \\
\hline$A * 3201$ & 586 & 1442 & & 1287 & 508 & 1061 & 630 & 1158 & $B * 3501$ & 787 & 1507 & 591 & 1509 & 720 & 1208 & 894 & 1134 \\
\hline A*3301 & 1166 & 2287 & 1007 & 2600 & 1208 & 1931 & 1376 & 1909 & $B * 3701$ & 1047 & 1774 & 700 & 2693 & 849 & 1503 & 1269 & 1595 \\
\hline$A * 3303$ & 1099 & 1989 & 964 & 2399 & 1205 & 1809 & 1171 & 1604 & $B * 3801$ & 783 & 1512 & 742 & 1752 & 894 & 1429 & 945 & 1309 \\
\hline A*3401 & 1915 & 2818 & 1217 & 2696 & 1525 & 2140 & 1938 & 2292 & $B * 3901$ & 812 & 1456 & 748 & 1924 & 956 & 1573 & 885 & 1292 \\
\hline A*3402 & 633 & 1354 & 526 & 1331 & 603 & 1183 & 738 & 1098 & $B * 4001$ & 1055 & 2177 & 747 & 2248 & 971 & 1841 & 1134 & 1781 \\
\hline$A * 3601$ & 814 & 1618 & 581 & 1424 & 657 & 1124 & 922 & 1251 & $B * 4002$ & 1108 & 2215 & 900 & 2596 & 1249 & 2088 & 1208 & 1890 \\
\hline$A^{*} 4301$ & 1235 & 2339 & 828 & 2335 & 1092 & 1718 & 1403 & 1959 & $B * 4006$ & 1568 & 2590 & 1081 & 2637 & 1314 & 2022 & 1631 & 2018 \\
\hline$A^{*} 6601$ & 1447 & 2543 & 890 & 2677 & 1112 & 2000 & 1438 & 1954 & $B * 4101$ & 808 & 1733 & 592 & 1793 & 759 & 1519 & 882 & 1494 \\
\hline$A^{*} 6602$ & 1142 & 2409 & 817 & 2493 & 1031 & 1867 & 1282 & 1997 & $B * 4201$ & 1166 & 2378 & 854 & 2456 & 1100 & 1982 & 1360 & 1952 \\
\hline$A * 6801$ & 538 & 1158 & & 1148 & & 959 & 607 & 896 & $B * 4402$ & 1800 & 2993 & 1514 & 3195 & 1809 & 2837 & 2120 & 2703 \\
\hline$A * 6802$ & 1091 & 2275 & 798 & 2629 & 955 & 1785 & 1219 & 1819 & $B * 4403$ & 1430 & 2514 & 1254 & 2908 & 1545 & 2466 & 1544 & 2110 \\
\hline$A * 6901$ & 1141 & 2009 & 778 & 1886 & 928 & 1547 & 1348 & 1755 & $B * 4501$ & 1410 & 2278 & 1126 & 2431 & 1440 & 2156 & 1483 & 1774 \\
\hline$A^{*} 7401$ & & 1039 & & 955 & & 731 & 532 & 846 & $B * 4601$ & 1547 & 2317 & 1302 & 2743 & 1596 & 2179 & 1592 & 1774 \\
\hline A*8001 & 3381 & 4716 & 2902 & 5608 & 3532 & 4362 & 3457 & 3883 & $B * 4701$ & 1021 & 1946 & 817 & 2115 & 1021 & 1663 & 1141 & 1675 \\
\hline HLA-Cw & & & & & & & & & $B * 4801$ & 1366 & 2546 & 1026 & 2586 & 1335 & 2331 & 1574 & 2068 \\
\hline $\mathrm{Cw}^{*} 0102$ & 2569 & 3608 & 2052 & 4142 & 2391 & 3199 & 2699 & 3011 & $B * 4901$ & 613 & 1397 & & 1191 & 587 & 1157 & 713 & 1119 \\
\hline $\mathrm{CW}^{*} 0202$ & 2787 & 3961 & 1778 & 4345 & 2333 & 2989 & 2810 & 3356 & $B * 5001$ & 601 & 1188 & & 1170 & 524 & 1037 & 607 & 1006 \\
\hline $\mathrm{Cw}^{*} 0302$ & 1960 & 2861 & 1590 & 3160 & 1854 & 2716 & 2036 & 2252 & $B * 5101$ & 1089 & 1969 & 761 & 1709 & 940 & 1492 & 1279 & 1578 \\
\hline $\mathrm{CW}^{*} 0303$ & 1963 & 2973 & 1554 & 3176 & 1903 & 2609 & 2145 & 2404 & $B * 5102$ & 1139 & 1888 & 649 & 1513 & 861 & 1317 & 1175 & 1502 \\
\hline $\mathrm{CW}^{*} 0304$ & 2224 & 3149 & 1705 & 3414 & 2046 & 2832 & 2436 & 2570 & $B * 5201$ & 1042 & 1699 & 606 & 1649 & 752 & 1292 & 1112 & 1398 \\
\hline $\mathrm{Cw}^{*} 0401$ & 2879 & 3949 & 1834 & 4359 & 2364 & 3124 & 3076 & 3162 & $B * 5301$ & 1638 & 2372 & 1410 & 2570 & 1594 & 2102 & 1831 & 2030 \\
\hline $\mathrm{CW}^{*} 0501$ & 2751 & 3704 & 2131 & 4470 & 2537 & 3295 & 2778 & 2953 & $B * 5401$ & 1434 & 2310 & 1091 & 2425 & 1295 & 1890 & 1536 & 1840 \\
\hline $\mathrm{Cw}^{*} 0602$ & 3350 & 4069 & 2093 & 5215 & 2647 & 3305 & 3499 & 3402 & $B * 5501$ & 644 & 1263 & & 1240 & & 975 & 685 & 967 \\
\hline $\mathrm{CW}^{*} 0702$ & 4316 & 5789 & 3328 & 8082 & 4154 & 5333 & 4627 & 4740 & $B * 5601$ & 665 & 1356 & & 1227 & 565 & 1125 & 741 & 1092 \\
\hline $\mathrm{CW}^{*} 0801$ & 1846 & 2904 & 1529 & 3436 & 1919 & 2752 & 1949 & 2325 & $B * 5701$ & 1164 & 2162 & 813 & 1934 & 1046 & 1826 & 1203 & 1737 \\
\hline $\mathrm{Cw}^{*} 1203$ & 2374 & 3364 & 2108 & 4081 & 2502 & 3147 & 2452 & 2642 & $B * 5703$ & 1545 & 2758 & 1080 & 2378 & 1395 & 2025 & 1742 & 2148 \\
\hline $\mathrm{CW}^{*} 1402$ & 2953 & 3921 & 2033 & 4236 & 2463 & 3073 & 3060 & 3296 & $B * 5801$ & 1285 & 1909 & 855 & 1792 & 1141 & 1604 & 1332 & 1584 \\
\hline $\mathrm{CW}^{*} 1502$ & 1795 & 2874 & 1580 & 3625 & 1889 & 2692 & 1960 & 2326 & $B * 5901$ & 1114 & 1894 & 773 & 1790 & 911 & 1320 & 1248 & 1543 \\
\hline $\mathrm{Cw}^{*} 1601$ & 1882 & 2646 & 1426 & 2912 & 1721 & 2202 & 2009 & 2041 & $B * 6701$ & 1549 & 2751 & 1373 & 3168 & 1717 & 2639 & 1680 & 2263 \\
\hline $\mathrm{CW}^{*} 1701$ & 5157 & 6618 & 3288 & 6424 & 4126 & 5245 & 4984 & 5530 & $B * 7301$ & 1502 & 2606 & 1370 & 3053 & 1776 & 2506 & 1541 & 1972 \\
\hline $\mathrm{CW}^{*} 1802$ & 3924 & 5008 & 3263 & 6884 & 3876 & 4594 & 4031 & 4062 & $B * 7801$ & 1193 & 1981 & 732 & 1997 & 867 & 1606 & 1265 & 1619 \\
\hline & & & & & & & & & $B * 8101$ & 1858 & 3214 & 1354 & 3371 & 1716 & 2747 & 1873 & 2579 \\
\hline & & & & & & & & & $B * 8201$ & 2690 & 4006 & 1865 & 3748 & 2280 & 3225 & 2739 & 3267 \\
\hline
\end{tabular}

IVIg was diluted from neat to $1 / 64$ and MFI was measured at all dilutions. Data is restricted to Neat and (1/2) dilution. The two most prevailing antibodies against each of the HLAA, HLA-B, and HLA-Cw loci are shown in Bold and Italics, suggesting the most prevalent anti-HLA IgG in IVIg pooled from the Moroccan male and female donors.

In contrast to MFI of anti-HLA-I IgG antibodies, the MFI of anti-HLA-II IgG antibodies remained high even at higher dilutions. All IVIg lots reacted to the panel of 91 HLA-II (29 HLA-DRB1, 3 HLA-DRB3, 2 HLA-DRB4, 2 HLA-DRB5, 29 HLA-DQ and 26 HLA-DP) alleles in the Single Antigen Beads assay. Figure 4 shows that the combined allelic mean MFI of the neat preparations of each IVIg lot (at a concentration of $50 \mathrm{mg} / \mathrm{mL}$ ) against the HLA-DRB1, - 
DRB345, -DQ, and -DP loci are higher than that of anti-HLA class I. The HLA-DRB1 reactivity of lot \#1, 2, 3, and 4 was $6108 \pm 1215,4050 \pm 1089,5345 \pm 1166$, and $5254 \pm 1238$, respectively. The HLA-DRB345 reactivity of lot \#1, 2, 3, and 4 was $5330 \pm 1525,3997 \pm 1851,5090 \pm 1681$, and $4859 \pm$ 1528, respectively. The HLA-DQ reactivity of lot \#1, 2, 3, and 4 was $4047 \pm 976,2634 \pm 915,3951 \pm 1066$, and $3473 \pm$ 922, respectively. The HLA-DP reactivity of lot \#1, 2, 3, and 4 was $4655 \pm 1439,3681 \pm 1369,4609 \pm 1508$, and $4277 \pm$ 1335, respectively. Essentially, all IVIg preparations showed stronger reactivity to HLA-DRB1 alleles, followed by HLA-DRB345 alleles, HLA-DP and then HLA-DQ alleles.

Table 4 provides a detailed profile of HLA-II reactivity of different lots of IVIg as MFI of individual allele of each HLA-II loci. The most prevalent anti-HLA-DR IgG antibodies in all Moroccan IVIg lots, as assessed by the MFI strength at neat and at all dilutions (data shown only for $1 / 2$ and 1/4 dilutions), are DRB3*03:03 and DRB1*03:02 (indicated by Bold italics). The lot \# 2 is the least expressed MFI for anti-HLA-DRB IgGs. Similarly, the most prevalent anti-HLA-DQ IgG antibodies in all the IVIg lots are DQB1*03:01\DQA $1 * 03: 01$ and DQB1*06:02 \DQA1*01:02, while DQB $1 * 02: 01 \backslash \mathrm{DQA} 1 * 02: 01$ remains the least expressed in all lots of IVIg. Among anti-HLA-DP IgG antibodies, MFI of DPB1*19:01\DPA1*01:03, DPB $1 * 23: 01 \backslash \mathrm{DPA} 1 * 02: 01$ and DPB $1 * 28: 01 \backslash \mathrm{DPA} 1 * 02: 01$ are the most predominant in all lots of the IVIg preparations.

Table 4. HLA-DR, HLA-DQ, and HLA-DP allelic reactivity of the four lots of Moroccan IVIg. IVIg was diluted from neat to 1/64 and MFI was measured at all dilutions.

\begin{tabular}{|c|c|c|c|c|c|c|c|c|c|c|c|c|}
\hline \multirow{2}{*}{$\begin{array}{l}\text { DR Alleles } \\
\text { Dilution }\end{array}$} & \multicolumn{3}{|c|}{ IVIg Lot 1} & \multicolumn{3}{|c|}{ IVIg Lot 2} & \multicolumn{3}{|c|}{ IVIg Lot 3} & \multicolumn{3}{|c|}{ IVIg Lot 4} \\
\hline & $(1 / 4)$ & $(1 / 2)$ & Neat & $(1 / 4)$ & $(1 / 2)$ & Neat & $(1 / 4)$ & $(1 / 2)$ & Neat & $(1 / 4)$ & $(1 / 2)$ & Neat \\
\hline DRB1*01:01 & & 1198 & 4361 & & 933 & 2757 & & 1167 & 3995 & 593 & 1114 & 4157 \\
\hline DRB1*01:02 & 877 & 1839 & 4595 & 790 & 1440 & 3533 & 820 & 2068 & 4777 & 964 & 1827 & 4404 \\
\hline DRB1*01:03 & 507 & 1200 & 4176 & & 1068 & 2747 & & 1375 & 3566 & 599 & 1187 & 3572 \\
\hline DRB1*03:01 & 1899 & 3681 & 7923 & 1653 & 3126 & 5874 & 1775 & 3941 & 7492 & 2210 & 3616 & 7256 \\
\hline$D R B 1 * 03: 02$ & 3226 & 5409 & 9762 & 3090 & 4552 & 7925 & 3046 & 5945 & 9425 & 3736 & 5457 & 9458 \\
\hline DRB1*04:01 & 1212 & 2351 & 6200 & 1061 & 1981 & 4221 & 1101 & 2743 & 5492 & 1438 & 2373 & 5683 \\
\hline $\mathrm{DRB} 1 * 04: 02$ & 1447 & 2956 & 6440 & 1218 & 2289 & 4349 & 1277 & 3154 & 5992 & 1716 & 2920 & 6039 \\
\hline DRB1*04:03 & 1621 & 2919 & 6840 & 1408 & 2467 & 4637 & 1429 & 3085 & 6289 & 1911 & 2895 & 6106 \\
\hline DRB1*04:04 & 1072 & 2275 & 6442 & 910 & 1917 & 4474 & 981 & 2393 & 5925 & 1296 & 2075 & 6108 \\
\hline DRB1*04:05 & 1377 & 2828 & 6169 & 1060 & 2170 & 4050 & 1179 & 2846 & 5332 & 1704 & 2694 & 5335 \\
\hline DRB1*07:01 & 620 & 1349 & 4784 & 543 & 1194 & 3273 & 625 & 1510 & 4529 & 717 & 1246 & 4030 \\
\hline DRB1*08:01 & 1618 & 2624 & 6803 & 1375 & 2319 & 5334 & 1352 & 2886 & 6399 & 1886 & 2663 & 5788 \\
\hline DRB1*09:01 & 1850 & 2435 & 5465 & 1924 & 2358 & 5184 & 1549 & 2798 & 5912 & 1865 & 2422 & 5254 \\
\hline DRB1*09:02 & 846 & 1641 & 4623 & 712 & 1376 & 3177 & 772 & 1826 & 4424 & 959 & 1602 & 4058 \\
\hline DRB1*10:01 & 1489 & 2816 & 6108 & 1259 & 2433 & 4633 & 1337 & 2786 & 5432 & 1654 & 2643 & 5720 \\
\hline DRB1*11:01 & 1130 & 2279 & 5766 & 915 & 1796 & 3697 & 929 & 2338 & 5249 & 1407 & 2260 & 4842 \\
\hline DRB1*11:04 & 1945 & 3351 & 7045 & 1608 & 2513 & 5071 & 1626 & 3444 & 6466 & 2225 & 3234 & 6185 \\
\hline DRB1*12:01 & 962 & 1796 & 5242 & 819 & 1644 & 3566 & 863 & 1981 & 5101 & 1147 & 1741 & 4574 \\
\hline $\mathrm{DRB} 1 * 12: 02$ & 1177 & 2243 & 6271 & 1008 & 1834 & 4315 & 1022 & 2415 & 5345 & 1479 & 2194 & 5497 \\
\hline DRB1*13:01 & 1258 & 2673 & 6122 & 1110 & 2020 & 3951 & 1168 & 2666 & 5766 & 1499 & 2472 & 5400 \\
\hline DRB1*13:03 & 725 & 1714 & 5359 & 611 & 1479 & 3669 & 657 & 1936 & 5049 & 889 & 1659 & 4700 \\
\hline DRB1*14:01 & 1163 & 2372 & 6168 & 1023 & 1802 & 3960 & 1032 & 2464 & 5369 & 1488 & 2310 & 5182 \\
\hline DRB1*14:02 & 1922 & 3058 & 6348 & 1648 & 2427 & 4830 & 1506 & 3146 & 6229 & 2215 & 2999 & 6269 \\
\hline $\mathrm{DRB} 1 * 14: 54$ & 1636 & 2809 & 6238 & 1435 & 2403 & 5072 & 1417 & 3106 & 5970 & 1945 & 2892 & 6127 \\
\hline DRB1*15:01 & 507 & 1029 & 3921 & & 917 & 2669 & & 1156 & 3786 & 571 & 916 & 3369 \\
\hline DRB1*15:02 & 707 & 1321 & 4557 & 600 & 1239 & 2944 & 604 & 1509 & 4103 & 836 & 1341 & 3660 \\
\hline DRB1*15:03 & 1044 & 2005 & 4983 & 804 & 1549 & 3854 & 856 & 2017 & 4767 & 1123 & 1841 & 4477 \\
\hline DRB1*16:01 & 1229 & 1912 & 5455 & 1070 & 1614 & 4232 & 1051 & 2189 & 5267 & 1228 & 1907 & 4858 \\
\hline DRB1*16:02 & 974 & 1789 & 5251 & 942 & 1720 & 3751 & 975 & 2072 & 4912 & 1131 & 1721 & 4773 \\
\hline DRB3*01:01 & 1511 & 2000 & 4806 & 1216 & 1500 & 3997 & 975 & 1973 & 5034 & 1546 & 2036 & 4399 \\
\hline DRB3*02:02 & 1275 & 2129 & 4826 & 1104 & 1774 & 3484 & 1060 & 2296 & 4590 & 1385 & 2080 & 4359 \\
\hline$D R B 3 * 03: 01$ & 5180 & 6075 & 8922 & 4947 & 5075 & 8629 & 4129 & 6499 & 9440 & 5189 & 5974 & 8562 \\
\hline DRB4*01:01 & 1586 & 2805 & 6676 & 1458 & 2169 & 4907 & 1390 & 2925 & 6219 & 1900 & 2647 & 5996 \\
\hline DRB4*01:03 & 810 & 1661 & 5330 & 609 & 1236 & 3477 & 628 & 1544 & 5090 & 899 & 1571 & 4859 \\
\hline DRB5*01:01 & 1517 & 2837 & 5981 & 1290 & 2410 & 4107 & 1302 & 2988 & 5436 & 1930 & 3057 & 5233 \\
\hline DRB5*02:02 & 806 & 1746 & 4656 & 726 & 1510 & 3542 & 792 & 2082 & 4886 & 919 & 1576 & 4280 \\
\hline \multicolumn{13}{|l|}{ DQ alleles } \\
\hline DQB1*02:01\DQA1*02:01 & & 990 & 2843 & & 821 & 1755 & & 1041 & 2495 & & 918 & 2447 \\
\hline DQB1*02:01\DQA1*03:01 & 732 & 1649 & 3742 & 617 & 1360 & 2522 & 643 & 1632 & 3107 & 900 & 1539 & 3180 \\
\hline DQB1*02:01\DQA1*04:01 & & 1116 & 3161 & & 857 & 2075 & & 1114 & 2989 & 546 & 1089 & 2750 \\
\hline DQB1*02:01\DQA1*05:01 & & 863 & 2873 & & 703 & 1566 & & 853 & 2646 & 515 & 752 & 2450 \\
\hline DQB1*02:02\DQA1*02:01 & & 1080 & 2937 & & 886 & 2039 & & 1157 & 2546 & 559 & 1085 & 2699 \\
\hline DQB1*03:01\DQA1*02:01 & 786 & 1732 & 4424 & 707 & 1586 & 3061 & 727 & 1960 & 4390 & 980 & 1661 & 3884 \\
\hline$D Q B 1 * 03: 01 \backslash D Q A 1 * 03: 01$ & 1656 & 3038 & 6368 & 1148 & 2332 & 3924 & 1260 & 2971 & 5973 & 2047 & 3135 & 5273 \\
\hline DQB1*03:01 \DQA1*05:03 & 655 & 1625 & 4820 & 618 & 1476 & 2855 & 758 & 1964 & 4557 & 793 & 1451 & 4090 \\
\hline DQB1*03:01\DQA1*05:05 & 652 & 1572 & 4690 & 633 & 1550 & 2873 & 769 & 1949 & 4655 & 831 & 1421 & 3901 \\
\hline
\end{tabular}




\begin{tabular}{|c|c|c|c|c|c|c|c|c|c|c|c|c|}
\hline \multirow{2}{*}{$\begin{array}{l}\text { DR Alleles } \\
\text { Dilution }\end{array}$} & \multicolumn{3}{|c|}{ IVIg Lot 1} & \multicolumn{3}{|c|}{ IVIg Lot 2} & \multicolumn{3}{|c|}{ IVIg Lot 3} & \multicolumn{3}{|c|}{ IVIg Lot 4} \\
\hline & $(1 / 4)$ & $(1 / 2)$ & Neat & $(1 / 4)$ & $(1 / 2)$ & Neat & $(1 / 4)$ & $(1 / 2)$ & Neat & $(1 / 4)$ & $(1 / 2)$ & Neat \\
\hline DQB1*03:01 \DQA1*06:01 & & 977 & 3285 & & 968 & 1931 & 480 & 1154 & 3373 & & 913 & 2502 \\
\hline $\mathrm{DQB} 1 * 03: 02 \backslash \mathrm{DQA} 1 * 01: 01$ & 1221 & 2211 & 4733 & 956 & 1730 & 3078 & 942 & 2261 & 4260 & 1536 & 2362 & 4353 \\
\hline DQB $1 * 03: 02 \backslash \mathrm{DQA} 1 * 02: 01$ & 999 & 1969 & 4645 & 852 & 1654 & 3328 & 867 & 2256 & 4561 & 1314 & 2069 & 4317 \\
\hline DQB $1 * 03: 02 \backslash$ DQA $1 * 03: 01$ & 1131 & 2448 & 5166 & 1040 & 2040 & 4090 & 1056 & 2585 & 5276 & 1392 & 2403 & 4504 \\
\hline DQB $1 * 03: 02 \backslash \mathrm{DQA} 1 * 03: 02$ & 606 & 1288 & 3684 & 593 & 1377 & 2364 & 694 & 1779 & 3951 & 814 & 1373 & 3196 \\
\hline $\mathrm{DQB} 1 * 03: 03 \backslash \mathrm{DQA} 1 * 02: 01$ & 548 & 1155 & 3571 & 536 & 1205 & 2207 & 589 & 1667 & 3473 & 736 & 1155 & 2880 \\
\hline DQB $1 * 03: 03 \backslash$ DQA $1 * 03: 01$ & 1047 & 2161 & 4969 & 926 & 1848 & 3436 & 948 & 2370 & 4727 & 1316 & 2201 & 4318 \\
\hline DQB $1 * 03: 03 \backslash \mathrm{DQA} 1 * 03: 02$ & 542 & 1196 & 3373 & 515 & 1255 & 2147 & 580 & 1535 & 3673 & 640 & 1179 & 2983 \\
\hline DQB $1 * 04: 01 \backslash \mathrm{DQA} 1 * 02: 01$ & 1057 & 2369 & 4701 & 857 & 1636 & 3248 & 882 & 2420 & 4218 & 1373 & 2280 & 4184 \\
\hline DQB $1 * 04: 01 \backslash \mathrm{DQA} 1 * 03: 03$ & 514 & 1068 & 2777 & & 843 & 1554 & & 1025 & 2322 & 719 & 1054 & 2368 \\
\hline DQB $1 * 04: 02 \backslash$ DQA $1 * 02: 01$ & 853 & 1924 & 4382 & 663 & 1426 & 2955 & 713 & 2102 & 4129 & 1081 & 1838 & 3913 \\
\hline DQB1*04:02\DQA $1 * 04: 01$ & 753 & 1666 & 4047 & 546 & 1279 & 2634 & 589 & 1693 & 3622 & 942 & 1589 & 3473 \\
\hline DQB $1 * 05: 01 \backslash \mathrm{DQA} 1 * 01: 01$ & 718 & 1389 & 3836 & 508 & 1006 & 1640 & 515 & 1180 & 2680 & 979 & 1502 & 2995 \\
\hline DQB $1 * 05: 02 \backslash \mathrm{DQA} 1 * 01: 02$ & 1128 & 2424 & 5212 & 833 & 1815 & 3395 & 858 & 2320 & 4934 & 1391 & 2266 & 4653 \\
\hline DQB $1 * 06: 01 \backslash \mathrm{DQA} 1 * 01: 03$ & 558 & 1173 & 3725 & & 825 & 1506 & & 1028 & 2804 & 824 & 1252 & 2902 \\
\hline DQB $1 * 06: 02 \backslash$ DQA $1 * 01: 01$ & 1175 & 2262 & 5345 & 966 & 1695 & 4119 & 976 & 2142 & 5216 & 1427 & 2164 & 4805 \\
\hline$D Q B 1 * 06: 02 \backslash D Q A 1 * 01: 02$ & 1320 & 2268 & 5403 & 1025 & 1826 & 4303 & 1041 & 2455 & 5086 & 1674 & 2455 & 4733 \\
\hline DQB $1 * 06: 03 \backslash \mathrm{DQA} 1 * 01: 03$ & 594 & 1295 & 3872 & & 764 & 1471 & & 1005 & 2613 & 854 & 1300 & 3377 \\
\hline DQB $1 * 06: 04 \backslash \mathrm{DQA} 1 * 01: 02$ & 1339 & 2637 & 6029 & 1111 & 2057 & 4006 & 1168 & 2749 & 5414 & 1664 & 2688 & 5670 \\
\hline DQB $1 * 06: 09 \backslash$ DQA $1 * 01: 02$ & 512 & 1132 & 3378 & & 719 & 1298 & & 906 & 2390 & 818 & 1166 & 2830 \\
\hline DP alleles & & & & & & & & & & & & \\
\hline DPB $1 * 01: 01 \backslash$ DPA $1 * 01: 03$ & 1409 & 2348 & 4911 & 1252 & 1992 & 3824 & 1234 & 2718 & 4920 & 1692 & 2383 & 4495 \\
\hline DPB1*01:01\DPA1*02:01 & 1686 & 2834 & 5989 & 1414 & 2269 & 4299 & 1455 & 2792 & 5709 & 2021 & 2689 & 5049 \\
\hline DPB $1 * 02: 01 \backslash D P A 1 * 01: 03$ & 1926 & 3162 & 5797 & 1538 & 2630 & 4193 & 1546 & 3056 & 5387 & 2369 & 3250 & 4694 \\
\hline DPB $1 * 03: 01 \backslash D P A 1 * 01: 03$ & 1183 & 2292 & 5208 & 1130 & 1903 & 3780 & 1051 & 2481 & 5052 & 1350 & 2234 & 4636 \\
\hline DPB1*03:01\DPA $1 * 01: 05$ & 1062 & 2059 & 4729 & 892 & 1639 & 3747 & 920 & 2134 & 4570 & 1242 & 2109 & 4371 \\
\hline DPB1*03:01\DPA1*02:01 & 1002 & 1578 & 4259 & 1005 & 1462 & 3473 & 989 & 1929 & 4416 & 1166 & 1584 & 3770 \\
\hline DPB $1 * 04: 01 \backslash D P A 1 * 01: 03$ & & 798 & 2612 & & 696 & 2120 & & 885 & 2753 & & 709 & 2389 \\
\hline DPB $1 * 04: 02 \backslash D P A 1 * 01: 03$ & 913 & 1637 & 4023 & 794 & 1475 & 3843 & 795 & 1817 & 4649 & 1047 & 1587 & 3941 \\
\hline DPB1*05:01\DPA $1 * 02: 01$ & 1280 & 1938 & 3963 & 1088 & 1583 & 3297 & 899 & 1883 & 4077 & 1538 & 1991 & 3644 \\
\hline DPB1*06:01\DPA1*02:01 & 1608 & 2601 & 5447 & 1476 & 2309 & 4938 & 1433 & 3127 & 5920 & 1714 & 2535 & 5127 \\
\hline DPB $1 * 09: 01 \backslash D P A 1 * 02: 01$ & & 912 & 3192 & & 768 & 2656 & & 1014 & 3185 & & 792 & 2904 \\
\hline DPB $1 * 10: 01 \backslash D P A 1 * 02: 01$ & 786 & 1469 & 3779 & 650 & 1182 & 2945 & 654 & 1598 & 3437 & 919 & 1444 & 3490 \\
\hline DPB $1 * 11: 01 \backslash \mathrm{DPA} 1 * 01: 03$ & 1997 & 2556 & 5071 & 1776 & 1989 & 5229 & 1617 & 2856 & 5970 & 1780 & 2384 & 4814 \\
\hline DPB1*11:01\DPA1*01:05 & 1675 & 3283 & 5968 & 1502 & 2508 & 4182 & 1448 & 3261 & 5224 & 2049 & 3267 & 5434 \\
\hline DPB1*13:01\DPA1*01:05 & 1458 & 2143 & 4396 & 1400 & 1816 & 3337 & 1239 & 2416 & 4467 & 1745 & 2282 & 4300 \\
\hline DPB $1 * 13: 01 \backslash D P A 1 * 02: 01$ & 1134 & 1885 & 4177 & 890 & 1318 & 3193 & 824 & 1697 & 4075 & 1514 & 1951 & 3710 \\
\hline DPB1*14:01\DPA1*02:01 & 1188 & 1984 & 4069 & 969 & 1595 & 3203 & 997 & 1988 & 4183 & 1437 & 1978 & 3882 \\
\hline DPB $1 * 15: 01 \backslash D P A 1 * 02: 01$ & 1844 & 2738 & 5923 & 1635 & 2370 & 5007 & 1469 & 2844 & 5738 & 2066 & 2672 & 5405 \\
\hline DPB1*17:01\DPA1*02:01 & 1142 & 2310 & 4582 & 949 & 1792 & 3393 & 950 & 2136 & 4717 & 1348 & 2171 & 4215 \\
\hline DPB $1 * 18: 01 \backslash D P A 1 * 02: 01$ & & 968 & 3556 & & 716 & 2350 & & 865 & 3098 & & 804 & 3146 \\
\hline DPB $1 * 18: 01 \backslash D P A 1 * 01: 04$ & 635 & 1205 & 3308 & 551 & 1049 & 2393 & 545 & 1201 & 3068 & 636 & 1132 & 3066 \\
\hline DPB1*18:01\DPA1*01:05 & 557 & 1216 & 3290 & & 980 & 2264 & 508 & 1088 & 3101 & 596 & 1113 & 2983 \\
\hline$D P B 1 * 19: 01 \backslash D P A 1 * 01: 03$ & 2573 & 3499 & 6735 & 2310 & 3063 & 5238 & 2019 & 3703 & 6712 & 3021 & 3678 & 6040 \\
\hline$D P B 1 * 23: 01 \backslash D P A 1 * 02: 01$ & 3187 & 3530 & 6809 & 3354 & 2839 & 7380 & 2257 & 3881 & 7784 & 3276 & 3619 & 6136 \\
\hline DPB $1 * 28: 01 \backslash D P A 1 * 01: 05$ & 1123 & 2116 & 4810 & 1000 & 1785 & 3615 & 1043 & 2275 & 4540 & 1280 & 1971 & 4253 \\
\hline$D P B 1 * 28: 01 \backslash D P A 1 * 02: 01$ & 2403 & 3241 & 5811 & 2466 & 2915 & 5370 & 2131 & 3702 & 6279 & 2679 & 3375 & 5629 \\
\hline
\end{tabular}

Data is restricted to Neat, $1 / 2$ and $1 / 4$ dilutions. Two or three most prevailing antibodies against each of the HLADR, HLA-DQ, and HLA-DP loci are shown in Bold and Italics, suggesting the most prevalent anti-HLA IgG in IVIg pooled from the Moroccan male and female donors.

\subsection{Unique Profile of Anti-HLA-I IgG in IVIg on iBeads}

HLA-Ia alleles on regular Labscreen single antigen beads may occur as intact or native trimeric HLA (HLA heavy chain and $\beta 2 \mathrm{~m}$ with peptide), as well as monomeric form such as heavy chain only, and dimeric form such as peptide-free heavy chain with $\beta 2 \mathrm{~m}$ or $\beta 2 \mathrm{~m}$-free heavy chain with peptide [43]. Whereas on iBeads, they may occur mostly as trimeric form HLA-I (peptide-associated heavy chain with $\beta 2 \mathrm{~m}$ ) or as dimeric form (peptide-free heavy chain with $\beta 2 \mathrm{~m}$ ) [43].
An MFI of an allele with iBeads that is higher than that of the regular bead would indicate that the HLA reactivity in question is toward intact or native trimeric HLA. Percentage of increase refers to the same [43]. In other words, an MFI of an allele with iBeads that is lower than that of the regular bead would indicate that the affinity of the antibody is towards other HLA-I variants such as the $\beta 2 \mathrm{~m}$-free HC of HLA with or without peptides. Percentage of decrease refers to the same.

In this investigation, the reactivity lot 3 of Moroccan IVIg (Table 5) to intact HLA-I (regular beads) and to heavy-chain HLA (iBeads) are compared. The percentage difference between regular beads and iBeads was calculated for every allele. The observations were restricted to the undiluted (neat) IVIg. The two most prevailing antibodies against the HLA-A, -B, and -Cw coated on iBeads are shown in (Bold 
Italics) in the Table 5. The density of the peptide associated or peptide-free HLA heavy chains with $\beta 2 \mathrm{~m}$ coated on HLA$\mathrm{A}$; - B; - $\mathrm{CW}$ antigen-coated iBeads in HLA-I Labscreen iBeads is $50 \% ; 54 \%$; $0 \%$ respectively.

Alternately, the density of $\beta 2 \mathrm{~m}$-free HLA heavy chains coated on HLA-A; -B; -Cw antigen-coated beads in HLA-I Labscreen beads is $19 \% ; 46 \% ; 100 \%$ respectively. Therefore, not all antibodies bound to the Labscreen beads can recognize the trimeric HLA -I molecule, occurring naturally on tissues. The IgG reactivity against alleles (e.g., $\mathrm{A}^{*} 0301$; A* 2901; A* 3402; A* 7401; B*1501; B*1503; B*1512; $\mathrm{B} * 4501 ; \mathrm{B} * 4901 ; \mathrm{B} * 5001 ; \mathrm{B} * 5501)$ is mainly due to antiHLA-I IgG binding to "intact" or "native" trimeric HLA (HLA heavy chain and $\beta 2 \mathrm{~m}$ with peptide).

Table 5. HLA-A, HLA-B, and HLA-Cw allelic reactivity of the lot 3 of Moroccan IVIg.

\begin{tabular}{|c|c|c|c|c|c|c|c|}
\hline \multicolumn{8}{|c|}{ MFI of the undiluted IVIg (neat) Lot 3} \\
\hline \multicolumn{4}{|c|}{ HLA-A } & \multicolumn{4}{|l|}{ HLA-B } \\
\hline Alleles & Regular & iBeads & $\% \mathrm{HC}+\beta 2 \mathrm{M}$ & Alleles & Regular & iBeads & $\% \mathrm{HC}+\beta 2 \mathrm{M}$ \\
\hline $\mathrm{A}^{*} 0101$ & 1389 & 687 & 49 & $\mathrm{~B} * 0702$ & 2701 & 1735 & 64 \\
\hline$A^{*} 0201$ & 1472 & 730 & 50 & B*0801 & 2909 & 1017 & 35 \\
\hline$A * 0203$ & 1324 & 901 & 68 & $\mathrm{~B} * 1301$ & 2022 & 540 & 27 \\
\hline$A * 0206$ & 1492 & 1093 & 73 & $\mathrm{~B} * 1302$ & 1719 & 1324 & 77 \\
\hline$A^{*} 0301$ & 576 & 666 & 115 & $\mathrm{~B} * 1401$ & 2157 & 829 & 38 \\
\hline$A^{*} 1102$ & 1183 & 994 & 84 & $\mathrm{~B} * 1501$ & 818 & 1055 & 129 \\
\hline$A * 2301$ & 1112 & 946 & 85 & $\mathrm{~B} * 1502$ & 1745 & 930 & 53 \\
\hline$A * 2402$ & 1768 & 1036 & 59 & $B * 1503$ & 912 & 1086 & 119 \\
\hline$A * 2403$ & 1750 & 1031 & 59 & $B * 1510$ & 1583 & 1003 & 63 \\
\hline$A * 2501$ & 1615 & 1301 & 81 & $\mathrm{~B} * 1511$ & 1428 & 673 & 47 \\
\hline$A * 2601$ & 1885 & 1263 & 67 & $B * 1512$ & 2742 & 3143 & 115 \\
\hline$A * 2901$ & 1860 & 2244 & 121 & $B * 1513$ & 1111 & 579 & 52 \\
\hline A*2902 & 2431 & 1942 & 80 & $\mathrm{~B} * 1516$ & 2015 & 822 & 41 \\
\hline$A * 3002$ & 1560 & 767 & 49 & $B * 2705$ & 1612 & 860 & 53 \\
\hline A*3101 & 1519 & 878 & 58 & $B * 2708$ & 2275 & 1296 & 57 \\
\hline$A * 3201$ & 1061 & 1052 & 99 & $B * 3501$ & 1208 & 960 & 79 \\
\hline$A * 3301$ & 1931 & 939 & 49 & $B * 3701$ & 1503 & 751 & 50 \\
\hline$A * 3303$ & 1809 & 843 & 47 & $\mathrm{~B} * 3801$ & 1429 & 652 & 46 \\
\hline$A * 3401$ & 2140 & 1264 & 59 & B*3901 & 1573 & 1069 & 68 \\
\hline$A * 3402$ & 1183 & 1354 & 115 & $B * 4001$ & 1841 & 759 & 41 \\
\hline$A * 3601$ & 1124 & 960 & 85 & $B * 4002$ & 2088 & 1292 & 62 \\
\hline$A * 4301$ & 1718 & 1364 & 79 & $B * 4006$ & 2022 & 787 & 39 \\
\hline$A * 6601$ & 2000 & 1500 & 75 & $B * 4101$ & 1519 & 728 & 48 \\
\hline$A * 6602$ & 1867 & 1261 & 68 & $B * 4201$ & 1982 & 1124 & 57 \\
\hline$A * 6801$ & 959 & 820 & 86 & $B * 4402$ & 2837 & 1025 & 36 \\
\hline$A * 6802$ & 1785 & 1133 & 63 & $B * 4403$ & 2466 & 786 & 32 \\
\hline$A * 6901$ & 1547 & 771 & 50 & $B * 4501$ & 2156 & 2466 & 114 \\
\hline A*7401 & 731 & 863 & 118 & $B * 4601$ & 2179 & 1081 & 50 \\
\hline $\mathrm{Cw}^{*} 0102$ & 3199 & 832 & 26 & $B * 4901$ & 1157 & 1304 & 113 \\
\hline $\mathrm{Cw} * 0202$ & 2989 & 608 & 20 & $\mathrm{~B} * 5001$ & 1037 & 1227 & 118 \\
\hline$C w * 0302$ & 2716 & 1326 & 49 & $B * 5101$ & 1492 & 986 & 66 \\
\hline $\mathrm{CW}^{*} 0303$ & 2609 & 1011 & 39 & $B * 5102$ & 1317 & 1015 & 77 \\
\hline $\mathrm{Cw}^{* 0304}$ & 2832 & 911 & 32 & B*5201 & 1292 & 1011 & 78 \\
\hline $\mathrm{CW}^{*} 0401$ & 3124 & 740 & 24 & $B * 5301$ & 2102 & 702 & 33 \\
\hline $\mathrm{CW}^{*} 0501$ & 3295 & 688 & 21 & $B * 5401$ & 1890 & 951 & $\mathbf{5 0}$ \\
\hline $\mathrm{Cw}^{*} 0602$ & 3305 & 729 & 22 & $\mathrm{~B} * 5501$ & 975 & 1213 & 124 \\
\hline $\mathrm{Cw}^{*} 0702$ & 5333 & 1117 & 21 & $B * 5601$ & 1125 & 632 & 56 \\
\hline$C w * 0801$ & 2752 & 1353 & 49 & $B * 5701$ & 1826 & 888 & 49 \\
\hline $\mathrm{Cw}^{*} 1203$ & 3147 & 952 & 30 & $B * 5703$ & 2025 & 755 & 37 \\
\hline $\mathrm{Cw}^{*} 1402$ & 3073 & 1218 & 40 & $\mathrm{~B} * 5801$ & 1604 & 560 & 35 \\
\hline $\mathrm{CW}^{*} 1502$ & 2692 & 904 & 34 & B*5901 & 1320 & 598 & 45 \\
\hline $\mathrm{CW}^{*} 1601$ & 2202 & 812 & 37 & $B * 6701$ & 2639 & 1441 & 55 \\
\hline $\mathrm{Cw}^{*} 1701$ & 5245 & 974 & 19 & B*7301 & 2506 & 1695 & 68 \\
\hline \multirow[t]{3}{*}{$\mathrm{Cw}^{* 1802}$} & 4594 & 725 & 16 & B*7801 & 1606 & 1143 & 71 \\
\hline & & & & B*8101 & 2747 & 747 & 27 \\
\hline & & & & $B * 8201$ & 3225 & 2139 & 66 \\
\hline
\end{tabular}

MFI obtained with regular Labscreen Beads and iBeads were compared for every allele of HLA-I locus. The data is restricted to undiluted (neat) IVIg. The percentage difference between regular beads and iBeads is shown for every allele in 
each locus. The two most prevailing antibodies, against each of the HLA-A, HLA-B, and HLA-Cw coated on iBeads, are shown in Bold and Italics.

\section{Discussion}

Four lots Moroccan IVIg preparations purified from pooled plasma of males and females of different ethnic groups and origins from different parts of the country were tested for reactivity to HLA-I, HLA-II and albumin using Luminex single antigen beads and for the antibody dimerization. In contrast to measuring MFI of serum antiHLA IgG, the MFI of anti-HLA IgG reactivity of IVIg is not affected by the presence of IgM or other classes of antibodies. The MFI values of IVIg indeed reflect HLA reactivity of IgG antibodies that binds to HLA coated beads.

Although it is known that the classical HLA-I and HLA-II molecules are highly polymorphic and represented by 2747 HLA-A, 3465 HLA-B, 2450 HLA-C, 7 HLA-DRA, 1711 HLA-DRB, 34 HLA- DQA1, 761 HLA-DQB1, 23 HLADPA1 and 627 HLA-DPB1 proteins [3], the number of HLA coated beads available for monitoring antibodies are far less (97 HLA-A, B and Cw and 91 HLA-DRA/DRB, DQA/DQB and DPA/DPB), thus imposing a limitation on characterizing the HLA antibodies prevailing in any population. In spite of the limitation, antibodies against high frequency alleles found in Moroccan population were observed.

The Moroccan IVIg preparations contain IgG antibodies against several high frequency HLA-I alleles found in the Moroccan population $\left(\mathrm{A}^{*} 0101, \mathrm{~A}^{*} 0201, \mathrm{~B}^{*} 0801, \mathrm{~B} * 4403\right.$, $\mathrm{B} * 4402, \mathrm{~B} * 5001, \mathrm{Cw} * 0401, \mathrm{CW}^{*} 0602$ and $\mathrm{CW}^{*} 0702$ ) [5]. The density of the antibodies as assessed by the levels of MFI for $\mathrm{B}^{*} 0801, \mathrm{~B}^{*} 5001, \mathrm{CW}^{*} 0602$ and $\mathrm{Cw}^{*} 0702$ are high parallel with their high frequency distribution. Similarly, the Moroccan IVIg had IgG antibodies against several high frequency HLAII alleles found in the Moroccan population [6], which include DRB $1 * 0701$, DRB $1 * 0301$, DQA $1 * 0501$, DQA $1 * 0201$, and DQB1*0201 and haplotypes DQA1*0201DQB $1 * 0201 / \mathrm{DRB} 1 * 0301$, which nearly account for $50 \%$ of the total gene frequencies found in Moroccan Souss cohort. These findings caution administering high dose IVIg for the carriers of the HLA types, because they may experience adverse effects such as TRALI. This investigation emphasizes the need to carry out HLA typing of any patient who receives Moroccan IVIg and if Moroccan IVIg is administered to these typed patients, a critical patient care is required at least for a week after administering high dose IVIg.

The HLA molecules on the tissues appear as different conformational variants. The most common configuration on normal tissues is considered to be an HLA trimer, which consists of a heavy chain (HC) $(40-45 \mathrm{kDa})$ non-covalently associated with $\beta 2$-microglobulin $(\beta 2 \mathrm{~m})(12 \mathrm{kDa})$ and an 8 10 amino acid long peptide that are bound in the $\mathrm{HC}$ groove. Frequently, the native HLA may also exist, devoid of the peptide, as a $\mathrm{HC}$ with $\beta 2 \mathrm{~m}$. Indeed, using Flow cytometric Cross match analyses, with epitope specific monoclonal antibodies, confirmed the prevalence of peptide-associated $\beta 2 \mathrm{~m}$-associated HLA HC (pepA- $\beta 2 \mathrm{aHC}$ ), on resting T-cells [43]. In addition to the above structural variants, a pool of $\beta 2 \mathrm{~m}$-free HLA as $\beta 2$-free $\mathrm{HC}(\beta 2 \mathrm{fHC})$ was observed in proliferating human lymphoid cells [45], and in activated human T and B cells [46, 47]. Binding of IVIg to activated T and B cells may bring about immunomodulation such as suppression of antibody production, which may be beneficial for patients with autoimmune diseases and organ transplants [48].

Jucaud and co-investigators [43] have carefully compared the conformational variants on the Labscreen regular Beads and iBeads, to confirm the striking differences between the two beads. They have confirmed that the two beads differ as follows:

(1) The presence and the heterogeneity of density of peptide-associated- $\beta 2 \mathrm{~m}$-associated HLA-heavy-chain (pepA- $\beta 2 \mathrm{aHC}), \quad$ peptide-free- $\beta 2 \mathrm{aHC}$ (pepF- $\beta 2 \mathrm{aHC})$, and $\beta 2$-free-HC $(\beta 2 \mathrm{fHC})$ on the regular Labscreen Single antigen beads.

(2) In contrast, iBeads harbored a high density of pepA$\beta 2 \mathrm{aHC}$ and low density of pepF- $\beta 2 \mathrm{aHC}$, but devoid of $\beta 2 \mathrm{fHC}$.

High prevalence of IgG antibodies for $81 \%$ of HLA-A and $54 \%$ HLA-B alleles on iBeads confirms the presence of IVIg antibodies reacting to normal tissue associated pepA- $\beta 2 \mathrm{aHC}$ and pepF- $\beta 2 \mathrm{aHC}$ variants. Such antibodies that bind to HLA trimers found on normal tissues are at potential risk for inflammatory diseases, such as TRALI.

However, IVIg reactivity to $\beta 2 \mathrm{fHC}$, which frequently found on activated $\mathrm{T}$ and $\mathrm{B}$ cells, and are responsible of increased production of antibodies in autoimmune diseases, may significantly suppress activated $\mathrm{T}$ and $\mathrm{B}$ cells involved, and thus alleviates autoimmune diseases. The dual functionality of HLA antibodies in IVIg emphasizes the need to modify the profiles of HLA antibodies to be directed against the HLA variants $(\beta 2 \mathrm{fHC})$ found on activated immune cells and may possibly have a beneficial influence on the patients with autoimmune diseases. Possibly the antibody profile can be modified by adsorbing out IgG antibodies directed against pepA or pepF- $\beta 2 \mathrm{aHC}$ using bead preparations like that of iBeads. Anticipating such benefits of IVIg, the US Federal Food and Drug Administration has recommended IVIg [51] for; (1) Primary Immune Deficiencies (PID), (2) Idiopathic Thrombocytopenic Purpura (ITP), (3) Chronic Lymphocytic Leukemia (CLL), (4) Kawasaki Disease, (5) Bone Marrow Transplantation (BMT). Again comparing the characteristics of IVIg from different manufacturers (Alpha, Baxter, Bayer, Centeon, Novartis), FDA has noted that while all the preparations are well suited for PID but not for all other above mentioned- disease conditions. The recent findings about HLA and IVIg has raised the necessity for screening HLA antibodies in different lots of Moroccan IVIg preparations and especially against the two kinds of HLA coated beads; one coated only with HLA-Trimer and the other one only with $\beta 2 \mathrm{fHC}$. Such a critical evaluation and the selection of lots reacting mostly to $\beta 2 \mathrm{fHC}$ would minimize adverse reactions (of course, without sucrose) and promote the 
utility value of IVIg for autoimmune diseases, and PID that are highly prevalent in Morocco. The dimer analysis emphasizes the need to examine the IgG subclasses in Moroccan IVIg preparations, since subclasses are different in their ability for dimerization [52-54].

\section{Conclusion}

HLA-I and HLA-II reactive high MFI IgG antibodies in the Moroccan IVIg corresponded with several high frequency HLA-I alleles (B*0801, B*5001, Cw*0602 and Cw*0702) and HLA-II haplotypes (DQA1*0201-DQB1*0201/DRB1*0301), which accounted for $50 \%$ of the total gene frequencies in the Moroccan population. Measuring anti-HLA-I IgG antibodies was performed using regular (Labscreen) Beads coated with all conformational and structural variants of HLA-I (pepA- and pepF- $\beta 2 \mathrm{aHC}$, pepA- and pepF- $\beta 2 \mathrm{fHC}$ ) and iBeads coated with native tissue-associated HLA-I trimers (pepA- $\beta 2 \mathrm{aHC}>$ pepF- $\beta 2 \mathrm{aHC}$ ). It was realized that the IVIg contains IgG antibodies against all of the structural variants. While HLA-A and HLA-B reactive antibodies in the four lots of IVIg were predominantly binding to native HLA-trimers, HLA-Cw reactive antibodies were mostly reactive to pepA and pepF $\beta 2 \mathrm{fHC}$. These findings caution use of high dose IVIg for the carriers of the high frequency HLA types for it may cause tissue injuries such as TRALI. The $\beta 2 \mathrm{fHC}$ reactivity of IVIg suggests the potential of IVIg to bind to activated T and B cells that overexpress $\beta 2 \mathrm{fHC}$, and to suppress antibody production.

\section{Acknowledgments}

We wish to express our sincere thanks to Dr M. Benajiba for providing the lots of Moroccan IVIg.

\section{Funding}

This research did not receive any specific grant from funding agencies in the public, commercial, or from any notfor-profit sectors.

\section{References}

[1] A. A. Bousfina, L. Jeddane, A. Conicno-Nato, Primary Immunodeficiencies in developing countries. In: Primary Immunodeficiency disorders. A historic and Scientific Perspective. (Eds.), Etzioni A, Ochs HD, Elsevier Inc. USA, 2014, pp. 65-76.

[2] F. El Hilali, H. El Hilali, M. F. Belahsen, A. El Idrissi, H. Mazouz, "Uses of Intravenous Immunoglobulin: A 13-Year Evaluation of Guillain-Barré Syndrome in Fez, Morocco," J Biol Med, vol. 1, pp. 001-005, 2017.

[3] HLA nomenclature. http://hla.alleles.org/nomenclature/, 2017 (accessed 06.05.17).

[4] F. Choukri, A. Chakib, H. Himmich, H. Raissi, S. CaillatZucman, "HLA class I polymorphism in a Moroccan population from Casablanca," Eur J Immunogenet, vol. 29, pp. 205-11, 2002.
[5] D. Piancatelli, A. Canossi, A. Aureli, K. Oumhani, T. Del Beato, M. Di Rocco, G. Liberatore, A. Tessitore, K. Witter, R. El Aouad, D. Adorno, "Human leukocyte antigen-A, -B, and $\mathrm{Cw}$ polymorphism in a Berber population from North Morocco using sequence-based typing," Tissue Antigens, vol. 63, pp. 158-72, 2004.

[6] H. Izaabel, H. J. Garchon, S. Caillat-Zucman, G. Beaurain, O. Akhayat, J. F Bach, A. Sanchez-Mazas, "HLA class II DNA polymorphism in a Moroccan population from the Souss, Agadir area," Tissue Antigens, vol.51, pp. 106-10, 1998.

[7] E. Gómez-Casado, P. del Moral, J. Martínez-Laso, A. GarcíaGómez, L. Allende, C. Silvera-Redondo, J. Longas, M. González-Hevilla, M. Kandil, J. Zamora, A. Arnaiz-Villena, "HLA genes in Arabic-speaking Moroccans: close relatedness to Berbers and Iberians," Tissue Antigens, vol. 55, pp. 239-49, 2000.

[8] K. Oumhani, A. Canossi, D. Piancatelli, M. Di Rocco, T. Del Beato, G. Liberatore, A. Aureli, A. Benjoaud, R. El Aouad, D. Adorno, C. U. Casciani, "Sequence-Based analysis of the HLA-DRB1 polymorphism in Metalsa Berber and Chaouya Arabic-speaking groups from Morocco," Hum Immunol, vol. 63, pp. 129-38, 2002.

[9] M. Kabbaj, M. Oudghiri, A. Naya, H. Naamane, S. Bennani, "Polymorphism of human leukocyte antigen-A, -B, and DRB1 in a Moroccan population from Casablanca: study of the allelic and the haplotypic frequencies," Ann Biol Clin (Paris), vol. 69, pp. 295-301, 2011.

[10] C. Brick, O. Atouf, M. Essakalli, "The HLA system in the Moroccan population: General review," Transfus Clin Biol, vol. 22, pp. 299-311, 2015.

[11] Z. V. Collins, P. F. Arnold, F. Peetoom, G. S. Smith, R. L. Walford, "A naturally occurring monospecific anti-HL-A8 isoantibody," Tissue Antigens, vol. 3, pp. 358-363, 1973.

[12] V. Lepage, L. Degos, J. Dausset, “A "natural” anti-HLA-A2 antibody reacting with homozygous cells," Tissue Antigens, vol. 8, pp.139-142, 1976.

[13] M. M. Tongio, A. Falkenrodt, Y. Mitsuishi, A. Urlacher, J. P. Bergerat, M. L. North, S. Mayer, "Natural HLA antibodies," Tissue Antigens, vol. 26, pp. 271-285, 1985.

[14] F. Ameglio, F. Saba, A. Bitti, A. Aceti, N. Tanigaki, R. Sorrentino, A. Dolei, R. Tosi, "Antibody reactivity to HLA classes I and II in sera from patients with hydatidosis," J. Infect. Dis, vol. 156, pp. 673-676, 1987.

[15] A. Ma'jsky', "Natural HLA-A, B and DR antibodies in the serum of nonimmunized men," Vnitr. Lek, vol. 35, pp. 467$471,1989$.

[16] M. A. Luscher, G. Choy, J. E. Embree, N. J. Nagelkerke, J. J. Bwayo, S. Njenga, F. A. Plummer, B. H. Barber, K. S. Mac Donald, "Anti-HLA alloantibody is found in children but does not correlate with a lack of HIV type 1 transmission from infected mothers," AIDS Res. Hum. Retroviruses, vol.14, pp. 99-107, 1998.

[17] B. Zhou, S. Saito, Y. Nakazawa, N. Kobayashi, M. Matsuda, Y. Matsumoto, T. Hosoyama, K. Koike, "Existence of an immunoglobulin $\mathrm{G}$ component of naturally occurring HLA class I antibodies that are not directed against self-antigens in human serum," Tissue Antigens, vol. 72, pp. 98-104, 2008. 
[18] L. E. Morales-Buenrostro, P. I. Terasaki, L. A. MarinoVa'zquez, J. H. Lee, N. El-Awar, J. Alberu', “"'Natural” human leukocyte antigen antibodies found in nonalloimmunized healthy males," Transplantation, vol. 86, pp. 1111-1115, 2008.

[19] M. H. Ravindranath, H. Kaneku, N. El-Awar, L. E. MoralesBuenrostro, P. I. Terasaki, "Antibodies to HLA-E in nonalloimmunized males: pattern of HLA-Ia reactivity of antiHLA-E-positive sera,” J Immunol, vol. 185, pp. 1935-48, 2010.

[20] M. H. Ravindranath, P. I. Terasaki, C. Y. Maehara, V. Jucaud, S. Kawakita, T. Pham, W. Yamashita, "Immunoglobulin (Ig)G purified from human sera mirrors intravenous Ig human leucocyte antigen (HLA) reactivity and recognizes one's own HLA types, but may be masked by Fab complementaritydetermining region peptide in the native sera," Clin Exp Immunol, vol. 179, pp. 309-3282015.

[21] M. H. Ravindranath, V. Jucaud, N. Banuelos, M. J. Everly, J. Cai, A. Nguyen, P. I. Terasaki, Nature and Clonality of the Fluoresceinated Secondary Antibody in Luminex Multiplex Bead Assays Are Critical Factors for Reliable Monitoring of Serum HLA Antibody Levels in Patients for Donor Organ Selection, Desensitization Therapy, and Assessment of the Risk for Graft Loss. J Immunol. 2017, DOI: https://doi.org/10.4049/jimmunol.1700050.

[22] D. W. King, E. Reed, N. Suciu-Foca, "Complexes of soluble HLA antigens and anti-HLA autoantibodies in human sera: possible role in maintenance of self-tolerance," Immunol Res, vol. 8, pp. 249-62, 1989.

[23] K. Zeki, F. Shirakawa, T. Fujihira, M. Kanatani, K. Watanabe, H. Suzuki, S. Eto, "Circulating monocyte (macrophage)specific antibodies in patients with autoimmune thyroid diseases," Clin Endocrinol (Oxf), vol. 31, pp. 1-13, 1989.

[24] M. C. Dooren, W. H. Ouwehand, A. J. Verhoeven, et al., "Adult respiratory distress syndrome after experimental intravenous gamma-globulin concentrate and monocytereactive IgG Abs," Lancet, vol. 352, pp. 1601-1602, 1998.

[25] A. Rizk, K. C. Gorson, L. Kenney, R. Weinstein, "Transfusion-related acute lung injury after the infusion of IVIG," Transfusion, vol. 41, pp. 264-268, 2001.

[26] P. V. Voulgari, S. Paschou, E. Svarna, et al, « Images in rheumatology. Transfusion-related acute lung injury during intravenous immunoglobulin treatment," Journal of Rheumatology, vol. 37, pp. 190-19, 2010.

[27] V. Gupta, P. Gupta, T. P. Yadav, "Transfusion related acute lung injury with intravenous immunoglobulin," Indian Pediatrics, vol. 48, pp. 807-808, 2011.

[28] D. R. Reddy, P. K. Guru, M. M. Blessing, J. R. Stubbs, A. A. Rabinstein, E. F. Wijdicks, "Transfusion-Related Acute Lung Injury after IVIG for Myasthenic Crisis," Neurocrit Care, vol. 23, pp. 259-261, 2015.

[29] R. Kumar, M. J. Sedky, S. J. Varghese, O. E. Sharawy, "Transfusion Related Acute Lung Injury (TRALI): A Single Institution Experience of 15 Years," Indian J. Hematol. Blood Transfusion, vol. 32, pp. 320-327, 2016.

[30] P. M. Kopko, T. G. Paglieroni, M. A. Popovsky, "TRALI: correlation of antigen- $\mathrm{Ab}$ and monocyte activation in donorrecipient pairs," Transfusion, vol. 43, pp. 177-184, 2003.

[31] P. M. Kopko, P. V. Holland, "Transfusion-related acute lung injury," British Journal of Haematology, vol. 105, pp. 322-

\section{9,2011}

[32] U. J. Sachs, "A threshold model for the susceptibility to transfusion-related acute lung injury," Transfusion Clinical Biology, vol. 19, pp. 109-116, 2012.

[33] D. Glotz, J. P. Haymann, N. Sansonetti, et al, "Suppression of HLA-specific alloAbs by high dose intravenous immunogloubulins (IVIg)," Transplantation, vol. 56, pp. 335337, 1993.

[34] D. Glotz, C. Antoine, J. P. Haymann, P. Julia, A. Doboust, J. Bariety, "Intravenous immunogloubulins and Kidney transplantation in patients with anti-HLA antibodies," Adv. Nephrol. Necker Hosp, vol. 30, pp. 221-233, 2000.

[35] N. El-Awar, A. Nikaein, M. Everly, J. Hopefield, A. Nguyen, "A Novel HLA Class I Single Antigen Bead Preparation Eliminates False Positive Reactions Attributed to Natural Antibodies - in the Sera of Normal Males and Pre-Transplant Patients," Hum Immunol, vol. 71 (2010) S26. DOI: 10.1016/j.humimm.2010.06.060.

[36] J. Szenczi, J. Kardos, A. Gyorgy, P. Závodszky, "The effect of solvent environment on the conformation and stability of human polyclonal IgG in solution," Biologicals, vol. 34, pp. 5-14, 2006.

[37] W. K. Bleeker, J. L. Teeling, A. J. Verhoeven, G. M Rigter, J, Agterberg, A. T. Tool, A. H. Koenderman, T. W. Kuijpers, C. E. Hack, "Vasoactive side effects of intravenous immunoglobulin preparations in a rat model and their treatment with recombinant platelet-activating factor acetylhydrolase," Blood, vol. 95, pp. 1856-61, 2000.

[38] United States Patent Number: 5,871,736. Bruegger et al., Date of Patent'. Feb. 16, 1999. Liquid immunoglobulin foreign patent documents formulations.

[39] D. Fenyo, Q. Wang, J. De Grasse, J. C. Padova, M. Cadene, B. T. Chait, MALDI Sample Preparation: the Ultra Thin Layer Method. JoVE. e192. 2007.

[40] Maldi-sample-preparation-the-ultra-thin-layer-method. https://www.jove.com/video/192/ maldi-sample-preparationthe-ultra-thin-layer-method. 2017 (accessed 06.05.17).

[41] M. H. Ravindranath, P. I. Terasaki, T. Pham, V. Jucaud, S. Kawakita, "Therapeutic preparations of IVIg contain naturally occurring anti-HLA-E antibodies that react with HLA-Ia (HLAA/-B/-Cw) alleles," Blood, vol. 121, pp. 2013-2028, 2013.

[42] J. Visentin, G. Guidicelli, T. Nong, M. J. Moreau. P. Merville, C. Lionel, J. Lee, J. Taupin, "Evaluation of the iBeads assay as a tool for identifying class I HLA antibodies," Human Immunol, vol. 76, pp. 651-6, 2015.

[43] V. Jucaud V, M. H. Ravindranath, P. I. Terasaki, "Conformational Variants of the Individual HLA-I antigens on Luminex Single Antigen Beads used in Monitoring HLA Antibodies: Problems and Solutions", Transplantation, vol. 101, pp. 764- 77, 2017.

[44] A. Zerrouki, S. Ouadghiri, N. Benseffaj, R. Razine, M. Essakalli, "High background in Luminex ${ }^{\circledR}$ assay for HLA antibody screening: Interest of Adsorb Out ${ }^{\mathrm{TM}}$," Transpl Immunol, vol. 36, pp. 20-24, 2016.

[45] E. Schnabl, H. Stockinger, O. Majdic, H. Gaugitsch, I. J. Lindley, D. Maurer, A. Hajek Rosenmayr, W. Knapp, "Activated human T lymphocytes express MHC class I heavy chains not associated with beta 2-microglobulin," J Exp Med, vol. 171, pp. 1431-1442, 1990. 
[46] J. Madrigal, A. Belichm, M. P. Benjamin, R. J, Little, A. M, Hildebrand, W. H, Mann, D. L. Parham, "Molecular definition of a polymorphic antigen (LA45) of free HLA-A and -B heavy chains found on the surfaces of activated $\mathrm{B}$ and $\mathrm{T}$ cells," J Exp Med. 174, 1085-1095, 1991.

[47] S. Demaria, R. Schwab, Y. Bushkin, "The origin and fate of beta $2 \mathrm{~m}$-free MHC class I molecules induced on activated $\mathrm{T}$ cells," Cell Immunol, vol. 142, pp. 103-113, 1992.

[48] D. Zhu, M. H. Ravindranath, P. I. Terasaki, T. Miyazaki, T. Pham, V. Jucaud, "Suppression of allo-human leucocyte antigen (HLA) Abs secreted by B memory cells in vitro: intravenous immunoglobulin (IVIg) versus a monoclonal antiHLA-E IgG that mimics HLA-I reactivities of IVIg," Clin. Exper. Immunol, vol. 177, pp. 464-477, 2014.

[49] M. H. Ravindranath, P. I. Terasaki, C. Y. Maehara et al.,"Immunoglobulin (Ig)G purified from human sera mirrors intravenous Ig human leucocyte antigen (HLA) reactivity and recognizes one's own HLA types, but may be masked by Fab complementarity determining region peptide in the native sera," Clin. Exper. Immunol, vol. 179, pp. 309-328, 2015.

[50] Powerpoint presentation of The ALPHA-TRAXTM Program.

[51] J. S. Finlayson, B. L. Armstrong, A. M. Young, "Reversibility of human immunoglobulin G dimerization," Acta Radiol Suppl, vol. 310, pp. 114-23, 1971.

[52] E. M. Yoo, L. A. Wims, L. A. Chan, S. L. Morrison, "Human IgG2 can form covalent dimers," J Immunol, vol. 170, pp. 3134-8, 2003.

[53] A. McAuley, J. Jacob, C. G. Kolvenbach, K. Westland, H. J. Lee, S. R. Brych, D. Rehder, G. R. Kleemann, D. N. Brems, M. Matsumura, "Contributions of a disulfide bond to the structure, stability, and dimerization of human IgG1 antibody CH3 domain," Protein Sci, vol. 17, pp. 95-106, 2008. 